\title{
RNA meets chromatin
}

\author{
Emily Bernstein and C. David Allis ${ }^{1}$ \\ Laboratory of Chromatin Biology, The Rockefeller University, New York, New York 10021, USA
}

In the universe of science, two worlds have recently collided-those of RNA and chromatin. The intersection of these two fields has been impending, but evidence for such a meaningful collision has only recently become apparent. In this review, we discuss the implications for noncoding RNAs and the formation of specialized chromatin domains in various epigenetic processes as diverse as dosage compensation, RNA interference-mediated heterochromatin assembly and gene silencing, and programmed DNA elimination. While mechanistic details as to how the RNA and chromatin worlds connect remain unclear, intriguing parallels exist in the overall design and machinery used in model organisms from all eukaryotic kingdoms. The role of potential RNA-binding chromatin-associated proteins will be discussed as one possible link between RNA and chromatin.

Chromatin, the intimate association of histone proteins and DNA into repeating nucleosomal units, is the physiologically relevant structure of our genome. An increasing body of evidence suggests that variation can be introduced into the chromatin polymer by an elaborate set of mechanisms that fail to alter the DNA template itself. The inheritance of chromatin states such as "active" (euchromatic) or "silent" (heterochromatic) domains forms the foundation of epigenetics. Until recently, understanding how, if at all, noncoding RNAs fit into the chromatin world, by influencing either euchromatin or heterochromatin, remained a puzzle that most biologists had simply not considered. Although the underlying mechanisms linking RNA and chromatin remain unclear, understanding how these epigenetic states are established and maintained during the life of a cell or development of an organism is imperative.

We favor the general view that a complete appreciation of epigenetic regulation is likely to require a careful examination of both RNA and chromatin fields. One goal of this review is to expose potential links between these two research areas, with a focus on transcriptional gene silencing in a wide range of experimental models.

[Keywords: RNAi; dosage compensation; heterochromatin; transcriptional gene silencing]

${ }^{1}$ Corresponding author.

E-MAIL alliscd@mail.rockefeller.edu; FAX (212) 327-7849.

Article and publication are at http://www.genesdev.org/cgi/doi/10.1101/ gad.1324305.
We conclude with a speculative model for how a group of heterochromatin-associated proteins may participate in linking RNA and chromatin.

\section{Chromatin dynamics}

The nucleosome is the fundamental repeating subunit of chromatin, consisting of an octamer of histone proteins (two copies of each of the four core histones H2A, H2B, $\mathrm{H} 3$, and H4) around which a defined segment (147 base pairs) of DNA is wound (Luger et al. 1997). Relatively unstructured histone "tail" domains are exposed on the nucleosomal surface and are rich in post-translational modifications such as serine and threonine phosphorylation, lysine acetylation, lysine and arginine methylation, lysine ubiquitination and sumoylation, and ADPribosylation (Strahl and Allis 2000; Zhang and Reinberg 2001). Emerging evidence suggests that covalent marks also exist in the histone-fold domains that correlate with the lateral surface of nucleosomes, near where critical histone:DNA interactions occur. Such modifications may mediate other aspects of chromatin structure (Cosgrove et al. 2004). Regardless of position or function, these covalent marks can be placed and removed by a variety of site-specific enzymes such as histone acetyltransferases (HATs) and histone deacetylases (HDACs), histone methyltransferases (HMTs), and the newly discovered "demethylating" activities (Cuthbert et al. 2004; Shi et al. 2004; Wang et al. 2004), ubiquitin ligases and deubiquitinases, and so on. Additional complexity and biological readout options are provided by the fact that certain modifications, such as methylation, can exist in mono-, di- and trimethylated forms, each of which is placed by a specific HMT. Finally, the notion that patterns of histone modifications can either coexist, on the same tail (cis) or on distinct tails (trans) that mediate potential "cross-talk" or "switching" between distinct marks and their binding partners (see below), has been formally proposed (Jenuwein and Allis 2001; Fischle et al. 2003a) and is currently under active investigation.

The sheer complexity of covalent histone modifications is multiplied by the existence of histone variants in many organisms, that give the cell added opportunities to change the overall composition of the nucleosome and its covalent modification potential (for review, see Kamakaka and Biggins 2005). In either the case of conventional or variant histones, the fundamental question of 
what covalent modifications actually do, remains. It has long been recognized that two general types of mechanisms exist that are certainly not mutually exclusive. These include trans mechanisms, which involve the binding of what we will refer to in this review as "effectors" that engage specific covalent marks in a contextdependent fashion, and cis mechanisms, which involve structural alterations in the chromatin fiber by changing internucleosomal contacts. Together, this variation may contribute to what has been referred to as a "histone code" (Turner 1993, 2000; Strahl and Allis 2000), which remains poorly understood.

Euchromatin and heterochromatin are often chromatin neighbors with important, and often antagonistic, cellular functions. For clarity, we divide our discussion between euchromatin (see green-shaded nuclei/chromosomes/chromatin in Figs. 1, 2) and heterochromatin (shaded red), focusing mainly on the latter. Historically,

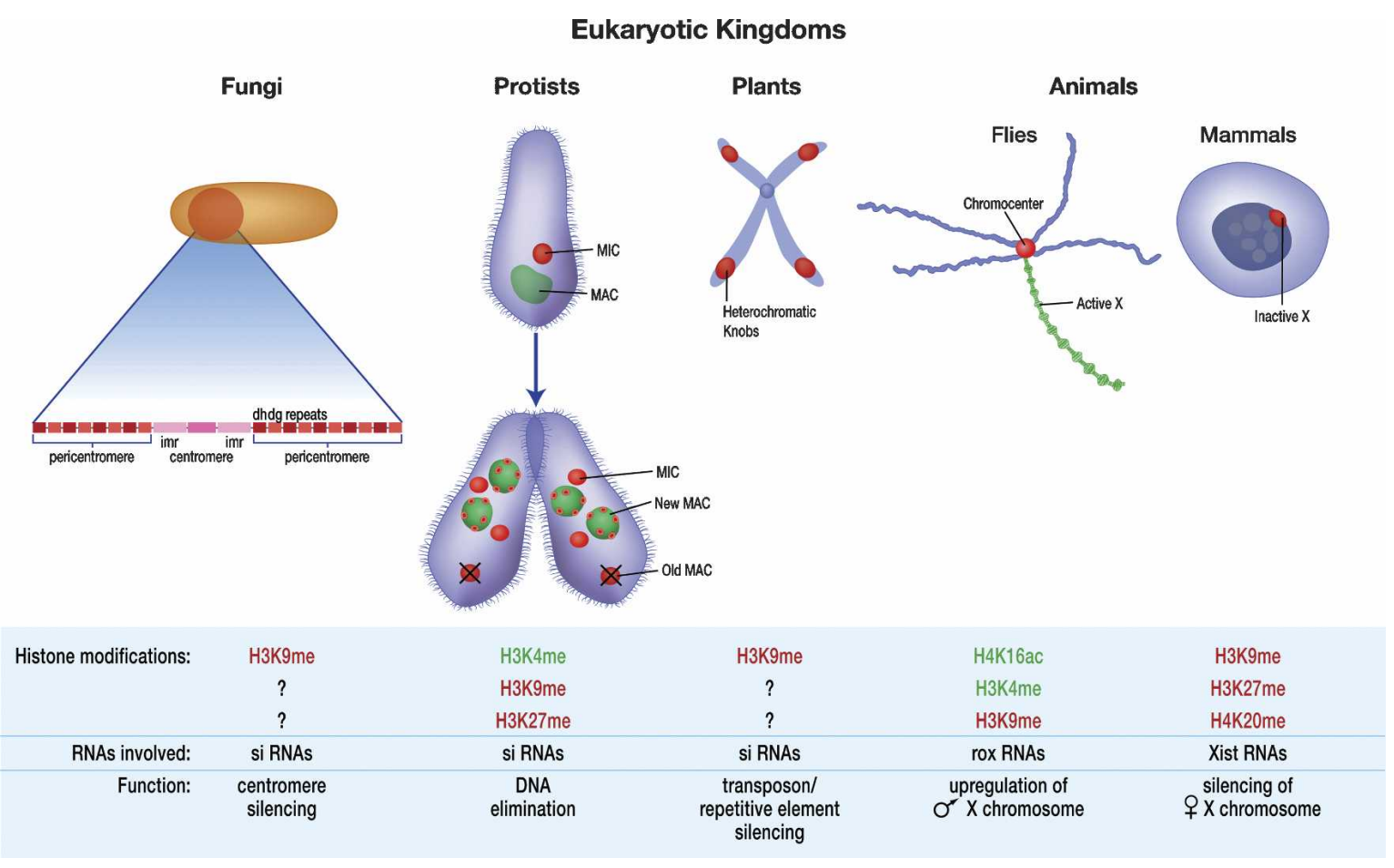

Figure 1. Chromatin and RNA regulation across eukaryotic kingdoms. Noncoding RNAs and histone modifications are involved in the formation of "active" chromatin (euchromatin is represented in green shading) or "inactive" chromatin states (heterochromatin is shown in red shading). Representing the kingdom of Fungi is the fission yeast, $S$. pombe, which mediates silencing of repetitive regions such as centromeres, mat loci, and telomeres through an RNAi-like mechanism. The diagram represents a $S$. pombe centromere. The innermost repeats (imr) of the centromere proper are shown in relation to the dh-dg repeats of the pericentromeric region, in which transcripts were detected in mutants defective for the RNAi machinery. The heterochromatin of the centromere is marked primarily by H3K9me (red), and possibly by other unidentified histone modifications. Representing the Protist kingdom is Tetrahymena thermophila, a binucleated ciliate that dramatically rearranges its genome during its sexual life cycle. (Top) In the vegetative state, the micronucleus (MIC) is the transcriptionally silent, germline nucleus (red), containing $100 \%$ of the sequence complexity of the organism. The macronucleus (MAC) is the transcriptionally active, somatic nucleus that governs the phenotype of the cell (green; histone modifications include H3K4me). (Bottom) At the time of DNA elimination, which occurs during conjugation, the MIC (red) has divided to form the new MAC and MIC, and subsequently the old MAC will be destroyed. The new MAC is active (green) with discrete ring-like structures (marked primarily by H3K9 and K27 methylation, red) in which IES DNA will be eliminated. siRNAs play a role in DNA elimination and heterochromatin formation in this protist, as represented by the "scan RNA" model (see Fig. 2). In the Plant kingdom, various mechanisms are at play to silence transgenes and repetitive elements. Heterochromatic "knobs" (red), first described in maize, are rich in transposable elements and satellite repeats, and are common in plant genomes. These knobs are regulated by siRNAs, H3K9me (red), and the chromatin-remodeling ATPase, DDM1 in Arabidopsis. Whether other histone modifications, such as H3K27me, are enriched in these regions, is currently unknown. Representing the Animal kingdom, flies and mammals both undergo a process of dosage compensation; twofold up-regulation of transcription of the male X in flies and silencing of the female $\mathrm{X}$ chromosome in mammals. The roX RNAs are integral to the dosage compensation complex in flies, and the active X chromosome is marked by histone modifications, such as $\mathrm{H} 3 \mathrm{~K} 4 \mathrm{me}$ and $\mathrm{H} 4 \mathrm{~K} 16 \mathrm{ac}$. The polytene chromosomes are represented, with the male $\mathrm{X}$ chromosome shown in green (active) and puffed due to transcription. The chromocenter, a transcriptionally inactive, tightly knit structure that contains the centromeres, is shown in red (silent) and is marked by H3K9me. In mammals, the female X chromosome is coated by the Xist RNA, which is critical for silencing, and is marked mainly by H3K9me, H3K27me, and H4K20me. siRNAmediated TGS also exists in flies and mammals (not illustrated here), but does not seem to play a role in dosage compensation in either animal. Note: Methylation states (mono, di, tri) have been excluded for simplicity (see text for details and references). 
heterochromatin has been somewhat of an enigma, in part because of its ability to affect neighboring genes. Chromosomal rearrangements in flies that place heterochromatin adjacent to euchromatin result in variegated silencing of nearby genes, a classical phenomenon known as position effect variegation (PEV) (Muller 1930; Wallrath and Elgin 1995; Schotta et al. 2003). Similarities between PEV and transposable elements in maize, which Barbara McClintock proposed to be located in heterochromatin more than 50 years ago, led to the hypothesis that heterochromatin might play a role in developmental regulation (McClintock 1951; see below).

Numerous studies suggest that euchromatin is often positively correlated with hyperacetylation of lysine residues on each of the core histones, as well as other active marks (e.g., methylation of Lys 4, Lys 36, and Lys 79 in H3). Conversely, common features of heterochromatin include deacetylated core histones and the addition of repressive marks (e.g., various degrees of methylation of Lys 9 and Lys 27 in H3 and Lys 20 in H4), DNA methylation, and the recruitment of repressive binding effectors such as heterochromatin protein 1 (HP1) and other methyl-binding proteins. Interestingly, this more compacted, higher-order chromatin state can be spread along silent domains and stably inherited (for review, see Elgin and Grewal 2003), although mechanistic details as to how this occurs are not yet clear. Moreover, heterochromatin plays a critical role in establishing chromosomal domains, such as centromeric, pericentromeric, and telomeric regions, that are vital for proper chromosome segregation (Allshire et al. 1995; Kellum and Alberts 1995; Grunstein 1997a; Karpen and Allshire 1997; Ekwall et al. 1999) and in less well-appreciated events such as programmed DNA elimination that distinguishes the germline from soma in some organisms (Fig. 1; Mochizuki and Gorovsky 2004). Thus, the relationship between euchromatin and heterochromatin, in part dictated by covalent modifications of histone proteins, provides an elegant balance for the regulation of epigenetic states, and may have much more significance than simply governing gene expression.

\section{RNA intricacies}

New evidence from a variety of model systems (Fig. 1) demonstrates that noncoding RNAs play a significant role in the control of epigenetic regulation, chromosomal dynamics, and long-range interactions, as well as phenomena that have an impact on normal cellular differentiation and organismal development. This includes mechanisms such as dosage compensation in flies and mammals, imprinting (for review, see Morey and Avner 2004; O'Neill 2005), and gene silencing by RNA interference (RNAi) phenomena in a variety of organisms.

Nowhere is the use of noncoding RNA in forming euchromatin versus heterochromatin better illustrated than with dosage compensation, a process that keeps the balance between the sex chromosomes (typically there exists two $\mathrm{X}$ chromosomes in females and one $\mathrm{X}$ chro- mosome and one Y chromosome in males). In both flies and mammals, noncoding RNAs are intimately involved in dosage compensation, as are changes in chromatin structure through histone modifications (Fig. 1; see below).

Considerable attention is currently being focused on RNAi-related silencing phenomena, processes that drastically alter gene expression among diverse species. Remarkable progress has been made in elucidating the mechanisms of RNAi that lead not only to post-transcriptional gene silencing (PTGS), but also to transcriptional gene silencing (TGS) (for review, see Hannon 2002; Grewal and Moazed 2003; Meister and Tuschl 2004; Sontheimer 2005; Tomari and Zamore 2005). This review will concentrate on emerging evidence that links RNAi-like mechanisms to the regulation of TGS through changes in chromatin.

Early evidence for an RNAi-like process directing epigenetic changes includes RNA-directed DNA methylation $(\mathrm{RdDM})$ in recombinant viroid-infected plants where double-stranded RNA (dsRNA) directed at the promoter region of a gene causes de novo cytosine methylation at homologous DNA sequences, resulting in stable silencing (Wassenegger et al. 1994; Pelissier and Wassenegger 2000; Jones et al. 2001). Underscoring another fundamental mechanism, a role for RNA in the establishment of heterochromatin formation has been uncovered from a series of elegant studies in fission yeast (Hall et al. 2002; Volpe et al. 2002) and plants (for review, see Gendrel and Colot 2005). Here, small RNA molecules that are products of the RNAi machinery can achieve TGS through chromatin changes, particularly characterized by histone methylation, and/or, in particular systems, DNA methylation. RNAi-mediated transcriptional gene silencing studies have also been extended to other model systems, such as Drosophila and mammals, leading to the emerging view that this is an ancient and universal mechanism, although the intricacies and details vary from one organism to the next.

Thus, while traditionally separate fields, new evidence provides hints and clues to the ways in which chromatin and RNA may be intertwined. Throughout this review, we focus on RNA-directed chromatin-based alterations, particularly those that are brought about by noncoding RNAs.

\section{Dosage compensation: a strong link between RNA and chromatin}

A growing number of studies suggest that noncoding RNAs are involved in a myriad of regulatory processes in the cell. One such process with a long history in the chromatin field is that of dosage compensation, a process that equalizes the output of transcription from the uneven number of $\mathrm{X}$ chromosomes found in male and females. Dosage compensation in both Drosophila and mammals is intimately linked to noncoding RNAs, which ultimately leads to changes in chromatin structure to either repress (mammals) or activate (Drosophila) 
transcription of X-linked genes (see Fig. 1). For clarity, each of these models is discussed separately.

\section{Dosage compensation in flies: linking RNA with active histone acetylation marks}

Transcription from the single male $\mathrm{X}$ chromosome in Drosophila is doubled in order to ensure equal levels of $\mathrm{X}$-linked genes in males and females. If this twofold transcriptional activation fails to occur properly, a male-specific lethal phenotype ensues. A ribonucleoprotein complex $(\mathrm{RNP})$ is involved in this process, namely, the dosage compensation complex (DCC, also referred to as the MSL complex). This complex is comprised of five core proteins, generally known as the MSL (male-specific lethal) proteins: MSL1, MSL2, MSL3, MLE (maleless, an RNA helicase), MOF (males absent on the first, a chromodomain-containing histone acetyltransferase or HAT), and a H3 Ser 10 kinase known as JIL, which interacts with the MSL proteins (for review, see Gilfillan et al. 2004). A key regulatory component of the DCC is MOF, which hyperacetylates $\mathrm{H} 4$ at Lys 16 and is, at least in part, responsible for the up-regulation of transcription from the X chromosome (Gilfillan et al. 2004). However, it remains unclear how this particular acetylation mark in $\mathrm{H} 4$, long known to be a residue critical for silencing in yeast in its unacetylated form (Kayne et al. 1988; Grunstein 1997b; Carmen et al. 2002), acts to bring about transcriptional up-regulation. It is tempting to speculate that Lys 16 acetylation either serves to recruit a positively acting effector to the male $\mathrm{X}$ chromosome or that this acetylation marks serves to displace a silencing factor. Relevant to the theme of this review, it remains of interest to know what role noncoding RNAs serve in this unique regulation of transcription (see below).

Two noncoding RNAs exist in the DCC, known as roX1 and roX2, which are essential components of the DCC complex and whose expression is male-specific. They are functionally redundant; only loss of both roX1 and roX2 dramatically affects male viability (Gilfillan et al. 2004). The MSL components are thought to assemble at $~ 35$ chromatin-entry sites along the male X chromosome, two of which encode the roX genes themselves. These sites serve as nucleation sites for spreading of the MSL complex into the flanking chromatin (Kelley and Kuroda 2000). The roX RNAs play an essential role in targeting the DCC to the X chromosome by mechanisms that remain unclear. Deletion of roX 1 and roX2 results in both mislocalization of the DCC complex and the acetylation of histone $\mathrm{H} 4$ at Lys 16 by the MOF histone acetyltransferase (Gu et al. 1998; Meller and Rattner 2002).

Interestingly, three of the DCC components are reputed RNA-interacting proteins, although the exact significance of these findings is not yet clear. The MLE helicase has an RNase-sensitive association with the $\mathrm{X}$ chromosome (Richter et al. 1996), and the chromodomain of MOF has been shown to bind RNA in vivo and in vitro and may represent a targeting mechanism for the DCC to the male X chromosome (Akhtar et al. 2000). Another component of the DCC complex, MSL3, con- tains two CDs, and this protein was also found to bind RNA in an in vitro setting (Akhtar et al. 2000). These findings may underscore a more general property of chromodomain-containing proteins: Do these proteins contain motifs permitting a novel mechanism for the targeting of proteins by RNA (see Fig. 3A,B)? In particular, is there a mechanism wherein RNAdirected recruitment of histone-modifying activities to a target locus (or in this case, entry sites along a chromosome) is likely to be involved in the critical regulation of gene dosage using either RNA:RNA or RNA:DNA base-pairing interactions (Fig. 3C)? Extending these ideas to mammals, we imagine that HMTs that catalyze more repressive, silencing marks on the inactive $\mathrm{X}$ chromosome, act in a similar fashion through a critical RNA association (see below). Support for this model comes from studies in flies, in which mutants lacking subunits of the DCC, particularly the RNA-binding components, show reduced binding to the male $\mathrm{X}$ chromosome (Richter et al. 1996; Gu et al. 1998). Understanding the precise mechanisms, or motif(s), that link the suspected RNA to chromatin remains an important challenge for the future.

\section{Dosage compensation in mammals: linking RNA with repressive histone methylation marks}

Remarkably, dosage compensation is handled quite differently in XX female mammals, where one of the two X chromosomes is inactivated to provide gene dosage between the sexes. In general, two types of X-chromosome inactivation have been well characterized in mice: (1) an imprinted inactivation mechanism that occurs in extraembryonic tissues that selects the paternal $\mathrm{X}$ chromosome to be silenced, and (2) a random mechanism in the embryo proper that occurs later in development and allows the female cell to "choose" which chromosome to inactivate (Heard 2004). We focus on the latter process. Random $\mathrm{X}$ inactivation is a multistep process involving choice of which chromosome to inactive, establishment of the inactive $\mathrm{X}$ state $(\mathrm{Xi})$, and maintenance of its silent state in subsequent cell divisions (Avner and Heard 2001).

Unlike in flies, where multiple chromatin-entry sites serve as docking sites for the DCC and from where the complex spreads in cis, inactivation in mammals is initiated at a single site known as the $\mathrm{X}$ inactivation center (Xic). The Xic produces multiple noncoding RNAs including Xist and its antisense RNA counterpart Tsix. Xist RNA is expressed exclusively from the X chromosome to be inactivated and is retained in the nucleus, where it coats the $\mathrm{X}$ chromosome. Xist RNA is $\sim 17 \mathrm{~kb}$ (depending on species) and is capped, spliced, and polyadenylated. The primary Tsix transcript covers at least $40 \mathrm{~kb}$, overlaps the full length of Xist, and regulates its expression; it too undergoes complex processing. Transcription of Tsix is thought to exert a repressive effect on the accumulation of Xist RNA at the onset of X inactivation, by mechanisms that are currently under investigation (Heard 2004). 
Interestingly, while the initiation of $\mathrm{X}$ inactivation is absolutely dependent on the Xist RNA, this RNA is not required for maintenance of the heterochromatic state of the Xi (Penny et al. 1996; Heard 2004). Deletions of Xist cause embryonic lethality in mice and in embryonic stem (ES) cells, and mutations in conserved regions of Xist, such as the $5^{\prime}$ stem-loop A-repeats, prevent the $\mathrm{X}$ chromosome from being inactivated (Penny et al. 1996; Marahrens et al. 1997; Wutz et al. 2002). Once Xist initiates $\mathrm{X}$ inactivation, a chain of chromatin-remodeling events occurs in order to ensure silencing. This includes the generation of hypoacetylated isoforms of histones $\mathrm{H} 3$ and $\mathrm{H} 4$, and methylation to varying degrees of residues Lys 9 and Lys 27 in H3 and Lys 20 in H4 (Fig. 1). Moreover, the inactive $\mathrm{X}$ incorporates a specialized H2A histone variant known as macroH2A (see below), although the significance of this variant residing in facultative heterochromatin is not known. In keeping with other forms of specialized heterochromatin, the inactive $\mathrm{X}$ is also marked by DNA methylation and replicates late in S phase (Heard 2004). Thus, this chromosome, but not its genetically identical sister, has become transformed into an epigenetically silent chromosome during development. This occurs, in part, by a redundancy of silencing marks that ensure its propagation into a stable heterochromatic state.

Enzymes that are responsible for "writing" repressive histone marks on the inactive X chromosome (e.g., dimethyl Lys 9 and trimethyl Lys 27 in H3 and monomethyl Lys 20 in H4) are slowly being uncovered. One such enzyme, E(z), a HMT that is a member of the Polycomb group (PcG) gene family, has been implicated in regulating Lys 27 methylation on the Xi (Plath et al. 2003; Silva et al. 2003). The PcG genes are required for maintaining stable repression of various genes during Drosophila development, including the homeobox (Hox) genes (for review, see Ringrose and Paro 2004). Collectively, there are $\sim 30-40$ members of this family, and mutations in these genes lead to homeotic transformations. The mouse counterparts of the Drosophila PcG genes ESC (Extra sex combs) and E(z) (Enhancer of zeste) are Eed (Embryonic ectoderm expression) and Enx1, respectively. These polypeptides form HMT complexes that methylate Lys 27 predominantly, and to a lesser extent, Lys 9 of histone H3 (Kuzmichev et al. 2002). Eed is a WD40-repeat protein required for the methyltransferase activity of $(\mathrm{E}) \mathrm{z}$. In mice deficient for Eed, $\mathrm{E}(\mathrm{z})$ is not recruited to the $\mathrm{Xi}$, nor is there any detectable Lys 27 methylation (Silva et al. 2003). Interestingly, in these mice, even though the $\mathrm{X}$ chromosome is still coated by $X i s t$, sporadic $\mathrm{X}$-linked gene reactivation and changes in chromatin structure have been observed, including $\mathrm{H} 3$ lysine acetylation and Lys 4 methylation, two "active" marks (Silva et al. 2003). Together, these data suggest that, although there is likely some redundancy between "repressive" marks, Lys 27 methylation plays a critical role in this epigenetic silencing. The HMT responsible for H3 Lys 9 methylation on the $\mathrm{Xi}$ is still somewhat of a mystery, although it has recently been shown that G9a dimethylates the Lys 9 hotspot in the
Xic that lies $5^{\prime}$ to Xist (Rougeulle et al. 2004). However, mice deficient for G9a have proper regulation of Xist expression and stable maintenance of the Xi /Ohhata et al. 2004). The HMT that monomethylates H4 Lys 20 on the $\mathrm{Xi}$ is currently unknown, although PR-SET7 is a likely candidate.

The Eed/E(z) complex is important for early maintenance of the inactive $\mathrm{X}_{\text {; }}$ however, there are other Xistindependent mechanisms for sustaining this inactive state. Due to their role in developmentally regulated repression in Drosophila, it had been proposed that the PcG genes might also be involved in the maintenance of silencing (Heard 2004). Recently, it has been shown that members of the PRC1 (Polycomb repressive complex 1) including Cbx2 (a mammalian Polycomb homolog containing a chromodomain), Polyhomeotic 1 and 2 (Phc), and Bmi1, are localized to the inactive X chromosome; some of these are recruited in a cell cycle-dependent manner (Plath et al. 2004; Hernandez-Munoz et al. 2005). Interestingly, accumulation of these proteins is not solely regulated by H3 Lys 27 methylation, but is dependent on the presence of the Xist RNA. The mechanistic link(s) between Xist RNA and the chromatin alterations described above are not known, and remain an important area for future research.

Overall, the inactive $\mathrm{X}$ is characterized by a series of covalent histone modifications that easily fit into the category of repressive marks (Fig. 1). It becomes of interest to compare these modifications to those on the active $\mathrm{X}$ chromosome or genes on the inactive $\mathrm{X}$ that "escape" inactivation. By chromatin immunoprecipitation (ChIP) analyses, promoter regions have been systematically compared on the inactive $\mathrm{X}$ with the homologous regions on the active X. While H3 Lys 9 and Lys 27 methylation is generally linked to gene silencing, genes on the active $\mathrm{X}$ display $\mathrm{H} 3$ Lys 4 methylation and hyperacetylation of histones $\mathrm{H} 3$ and $\mathrm{H} 4$ (Goto et al. 2002). Moreover, the chromatin signature of genes escaping $\mathrm{X}$ inactivation includes $\mathrm{H} 3$ Lys 4 methylation, hyperacetylation of $\mathrm{H} 3$, and hypoacetylation of $\mathrm{CpG}$ islands surrounding these genes (Goodfellow et al. 1988; Boggs et al. 2002; Filippova et al. 2005). Exactly how this separation of inactive and active chromatin along the $\mathrm{X}$ chromosome is achieved is not known, but it may be regulated by insulator and/or boundary elements (Filippova et al. 2005). In some ways, these findings are reminiscent of the large-scale genomic indexing relationships between Lys 4 and Lys 9 methylation that occur along domains of the chicken $\beta$-globin locus (Litt et al. 2001) and the mating-type locus in fission yeast (Noma et al. 2001).

\section{Heterochromatin meets RNAi}

RNA interference is a relatively novel silencing process that was discovered serendipitously in Caenorhabditis elegans when researchers were attempting to use antisense RNA approaches to knock down gene function (Guo and Kemphues 1995). Unexpectedly, sense RNA gave essentially the same knock-down effects as antisense RNA, 
an inexplicable observation at the time. Mello and Fire then demonstrated that double-stranded RNA was the trigger for the observed potent gene silencing (Fire et al. 1998). This seminal discovery led to the identification of RNAi as a widespread gene-silencing mechanism used by many organisms. Besides being a valuable research tool, the mechanism of RNAi is a fascinating one. The effects of RNAi can be threefold; this process can result in messenger RNA degradation, translational inhibition, chromatin changes, or possibly even a combination of these.

A brief discussion of the principal components of the RNAi machinery is necessary in order to appreciate RNAi-mediated TGS mechanisms. It has been recognized for some time that the "canonical" RNAi pathway uses small interfering RNAs (siRNAs) to induce degradation of cognate messenger RNAs in a sequence-specific manner (for review, see Hannon 2002; Meister and Tuschl 2004). This involves the processing of dsRNA by Dicer, the RNA substrate of which may be exogenously introduced by experimental manipulation, viruses, endogenous parasitic elements, or repetitive sequences. The enzyme Dicer belongs to the RNase III family of ribonucleases, which creates, through its action, small interfering RNAs (siRNAs) that are central to RNAi and related phenomena. These small RNAs are then loaded into dedicated machinery, known as the RISC complex (RNA-induced silencing complex), whose nuclease activity is encoded by the Argonaute- 2 protein (Liu et al. 2004; Meister et al. 2004; Song et al. 2004). RNAi is also involved in the regulation of translation, in which endogenous microRNA precursors (pre-miRNAs) are sequentially processed by the Drosha and Dicer RNase III enzymes, yielding microRNAs (miRNAs). miRNAs bind the $3^{\prime}$-UTR of their target genes and inhibit translation by a currently unknown mechanism (for review, see Carmell and Hannon 2004; Cullen 2004). Through various cloning studies, it is becoming clear that scores of miRNAs are encoded in the genome in a variety of organisms, ranging from viruses to plants to mammals (for review, see He and Hannon 2004; Pfeffer et al. 2004). miRNAs are responsible for key processes of development such as patterning, cell symmetry, and proliferation (Brennecke et al. 2003; Johnston and Hobert 2003; Palatnik et al. 2003; Juarez et al. 2004; Kidner and Martienssen 2004), and are implicated in disease (Poy et al. 2004). However, RNA degradation and translational inhibition, both PTGS mechanisms, are not the focus of this review. Instead, we focus on RNAi-mediated TGS effects such as chromatin modifications, particularly histone methylation. Like PTGS, this silencing is instigated or "guided" by a subset of small RNAs generated by the RNAi machinery.

The idea that an RNAi-like mechanism could target locus-specific domains for chromatin alterations was not anticipated. RNAi has now been demonstrated to have transcriptional gene-silencing effects, most notably through the establishment of heterochromatin in fission yeast. RNAi-mediated chromatin effects have also been uncovered in organisms as diverse as Tetrahymena, Drosophila, and mammals, but the detailed mechanisms have yet to be revealed. The discovery that RNAi plays a role in heterochromatin formation came from landmark genetic studies that investigated the effects of defective RNAi machinery on the silencing that occurs at centromeres and mating-type loci in Schizosaccharomyces pombe (Hall et al. 2002; Volpe et al. 2002; see below).

\section{RNAi and repetitive elements}

In all complex genomes, endogenous repetitive elements, as well as multiple copies of defective and intact transposable elements, form a significant fraction of the genomic complexity. These elements, which have been described as "junk" DNA, are often assembled into condensed, transcriptionally silent chromatin states (heterochromatin), in part due to the combined action of histone and/or DNA covalent modifications, notably methylation (see below for discussion of centromeres). Suppression of these elements is essential for genetic stability in two ways: Intact transposons are potential mutagens if integrated into coding genes, and repetitive sequences are potential sites for nonhomologous crossovers.

RNAi-like mechanisms are now known to play a critical role in mediating heterochromatic gene silencing and can prevent the mobilization of transposable elements (Matzke et al. 2000; Sijen and Plasterk 2003). Clear evidence has come from studies in C. elegans in which RNAi-deficient worms show high rates of transposition (Ketting et al. 1999; Tabara et al. 1999). In Drosophila, I elements (similar to mammalian LINE elements) can be silenced by previous introduction of transgenes expressing a small region of the transposon (Jensen et al. 1999). Defects of RNAi were also found to relieve silencing of tandem transgene arrays in Neurospora crassa and Arabidopsis (Cogoni and Macino 1999; Mourrain et al. 2000). In the mouse embryo, knock-down of Dicer results in an increase in retrotransposon (IAP and MuERVL) transcript abundance, suggesting that RNAi constrains expression of repetitive parasitic sequences in the preimplantation embryo (Svoboda et al. 2004a). Furthermore, in an effort to identify endogenous targets of RNAi, the sequencing of small RNAs has revealed sequences corresponding to endogenous transposons and other repetitive sequences in Drosophila and plants (Hamilton et al. 2002; Llave et al. 2002; Aravin et al. 2003). Although the underlying mechanism of these processes is still under investigation, together these results indicate that RNAi has evolved, in part, to maintain genomic stability and may be a conserved mechanism across species.

Because RNAi is central to heterochromatin formation, the intuitive belief that silent chromatin is not transcribed (and therefore, that RNA is not available or required to initiate silencing) needs to be challenged. "Readthrough" transcription of the aforementioned repetitive elements, for example, can produce dsRNAs that initiate silencing. Bidirectional transcription has been detected in mutant plants that are defective for silencing, including met1, a DNA methyltransferase, and 
ddm1 (decrease in DNA methylation), a SWI2/SNF2-related chromatin-remodeling protein (Lippman et al. 2004). Once dsRNA is generated, it can then be processed into small RNAs through the Dicer family of RNase III enzymes and fed into the appropriate silencing machinery. Underscoring the generality of these mechanisms, centromeric repeats are transcribed in $S$. pombe (Volpe et al. 2002) as are micronuclear germline sequences in Tetrahymena (Chalker and Yao 2001), a nucleus often described as being "silent" (see below).

An intriguing hypothesis has been put forward to explain how tandem arrays are important for the maintenance of silencing (Martienssen 2003). In some organisms, including C. elegans, plants, and fission yeast, a mechanism is in place to amplify the RNA signal, namely, an RNA-dependent RNA polymerase (RdRP). Given that mutations of the RdRP in various systems abolish silencing, tandem repeats may be distinguished from dispersed repeats by their inherent ability to sustain RdRP activity over multiple rounds of RNAi (due to the fact that the primer for the RdRP, the small RNAs, would be unlimited in tandem arrays). However, dispersed or single-copy elements would eventually lose RNAi capability since their supply of primers would eventually be depleted. This model is tantalizing; however, it does not account for the fact that RdRPs do not necessarily require a primer and cannot be applied to Drosophila and mammals that appear to lack RdRP enzymes (Makeyev and Bamford 2002).

Recent mapping studies in plants and mammals have suggested that repetitive elements are strongly correlated with histone methylation and the production of RNA. In Arabidopsis, mapping across large chromosomal regions containing heterochromatic knobs (Fig. 1) has revealed a robust correlation between DNA repeats, DNA methylation, noncoding RNA, and histone H3 Lys 9 methylation (Lippman et al. 2004). In addition, a profile analysis of histone methylation states (H3 Lys 9, Lys 27, and H4 Lys 20 in the mono-, di-, and trimethylated forms) has been performed on repeat-associated sequences in the mouse genome (Martens et al. 2005). Tandem repeats such as the major and minor satellite sequences were examined, as well as other repetitive elements, including various transposons. In accord with the model described above, tandem repeats, but not interspersed elements, were found to give rise to dsRNAs. Interestingly, the level of these RNAs is elevated in cells deficient for the SUV39H histone methyltransferases (Martens et al. 2005). This finding leads to the intriguing possibility that recruitment of RNAi processing complexes is impaired in the absence of H3 Lys 9 methylation at these repetitive regions, an analogous situation to the silencing of centromeres in fission yeast (see below).

\section{RNAi and centromeres}

Heterochromatin stabilizes repetitive DNA sequences or multiple copies of transposable elements at centromeres, telomeres, and other regions of the genome by prevent- ing recombination between homologous sequences (Karpen and Allshire 1997; Csink and Henikoff 1998). S. pombe has provided an excellent model system in which to investigate the role of RNAi-induced TGS at these regions. Using this organism, several groups have demonstrated that small RNAs play a critical role in regulating heterochromatin formation. The first of these studies examined the loss-of-function effects of various RNAi genes, including dicer (dcr1), Argonaute 1 (ago1), and the RNA-dependent RNA polymerase $(r d p 1)$, each the sole genes of their kind in this yeast (Hall et al. 2002; Volpe et al. 2002). Disruption of these genes resulted in the elimination of silencing of a ura4 marker gene inserted into the inner and outer repeats of the centromere, similar to the effects of disrupting the swi6 (HP1 homolog) and clr4 (H3 Lys 9 HMT) genes (Ekwall et al. 1996; Volpe et al. 2002). In addition, a corresponding loss of H3 Lys 9 methylation was observed. The loss of silencing at the centromeres results in catastrophe for the cell, including abnormal chromosome segregation (Ekwall et al. 1995; Partridge et al. 2002; Provost et al. 2002). Similar studies, performed at the mating-type locus (mat), which contains sequences homologous to the centromeric repeats, illustrated that the RNAi machinery was also required for silencing at this region. However, while RNAi is involved in the establishment and maintenance of silencing at the centromeres, it is involved exclusively in the establishment of the mat locus (Hall et al. 2002).

The RNAs involved in establishing this transcriptional silencing have been highly sought after. Long, noncoding RNAs homologous to the centromeric repeats were found to accumulate in the dcr1, ago1, and $r d p 1$ mutant cells, but not in wild-type cells. Nuclear run-on experiments suggested that these RNAs are continuously being made in wild-type cells, but are actively diced into small RNAs and thus are not detected (Volpe et al. 2002). The small RNAs homologous to the centromeric repeats have been detected by various means in fission yeast, including small RNA cloning studies that revealed abundant species homologous to the centromeric sequences (Reinhart and Bartel 2002).

An important breakthrough in understanding the mechanism of TGS came with the biochemical purification of complexes that contain the small RNAs crucial to this process. A RNP complex known as RITS (RNAinduced transcriptional silencing)-which contains Ago1, Chp1 (a chromodomain-containing protein), and a novel protein of unknown function referred to as Tas3was purified from S. pombe (Verdel et al. 2004). The RNAs in this complex are thought to direct sequencespecific targeting of the RNAi machinery to homologous sequences (see Fig. 3C). In addition, ChIP experiments suggest that the RITS complex is bound to all known heterochromatic loci, including centromeres, telomeres, and the mat locus (Volpe et al. 2002; Noma et al. 2004). RITS association with these loci is dependent on H3 Lys 9 methylation, and the chromodomain of Chp1 is thought to recognize and bind to this histone modification as a "docking" effector. Importantly, loading of this complex with small RNAs and tethering it to chromatin 
is essential for silencing and for the generation of additional siRNAs required to bring about heterochromatin formation. The RITS complex has been found to interact with another complex through Agol in an siRNA-dependent manner. This complex, RDRC (RNA-dependent RNA polymerase complex), contains Rdp1, a novel RNA helicase and an intriguing member of the poly A polymerase family (Motamedi et al. 2004). Cells defective for these proteins fail to localize RITS to centromeric regions and initiate heterochromatin assembly. Moreover, both RITS and RDRC localize to noncoding centromeric transcripts (Motamedi et al. 2004).

The collective model arising from these exciting studies suggests a critical role for RNAi in the establishment of heterochromatin at repetitive loci. In such a model, these repeats generate RNAs that can be double-stranded in nature or form dsRNA intermediates, which are then processed by the RNAi machinery in the nucleus to produce small RNAs. These RNAs may serve as "guides" for targeting histone methyltransferase complexes to the chromatin, such as the H3 Lys 9 HMT, Clr4, although this mechanism is not yet understood. Once such a guiding RNA mark is positioned, through base-pairing with its complementary DNA sequence or nascent transcript (as seems the case for centromeric regulation), complexes analogous to RITS can dock onto modified sites through methyl-histone recognition by chromodomaincontaining proteins (see Figs. 2, 3). This mechanism would facilitate silencing and subsequent spreading by HP1 and its homologs, and may represent a self-enforcing loop to maintain silencing at specific loci, such as centromeres and other highly repetitive regions of the genome. Although H3 Lys 27 methylation has not yet been reported in fission yeast, it is appealing to investigate whether RNAi can direct this inactive chromatin mark in other systems as well (Fig. 1).

The mechanism of centromeric silencing described above may be conserved among species. The link between RNAi and heterochromatin formation has certainly been established in plants. For example, an Argonaute family member in Arabidopsis, Ago4, is required for locus-specific siRNA accumulation as well as DNA and histone methylation (Zilberman et al. 2003). In addition, it has been described in mammalian cells that an RNA component is required for the integrity of pericentric heterochromatin (Maison et al. 2002), and embryonic stem cells deficient for the RNAi machinery, particularly Dicer, have centromeric silencing defects (Kanellopoulou et al. 2005; see below). Interestingly, the only known PcG-binding sites in mammals consist of pericentromeric heterochromatin repeats (Saurin et al. 1998). Determining the sequential order of these proposed steps and learning the identity of all binding adaptors or effectors remain important areas for future investigation.

\section{RNAi and DNA elimination}

DNA elimination is considered by some to be the "ultimate form of gene silencing" (Mochizuki and Gorovsky
2004). Ciliated protozoans such as Tetrahymena and Paramecium are binucleated unicellular organisms that rearrange their genomes significantly during the developmental process of conjugation (Figs. 1, 2; for review, see Prescott 1994). During vegetative growth, the nonsexual phase of the life cycle, these ciliates contain two functionally distinct nuclei within the same cytoplasm, namely, a micronucleus (MIC) and a macronucleus (MAC). The macronucleus is responsible for transcriptional activity and is thus analogous to the somatic nucleus of a metazoan; it is responsible for determining the phenotype of the cell and is polyploid. The micronucleus, in contrast, is transcriptionally silent and diploid; it is considered the germline nucleus containing $100 \%$ of the sequence complexity of the organism. During the sexual process of conjugation, the micronucleus divides to form the next generation of macro- and micronuclei, and concomitant with formation of new macronuclei, the old (parental) macronucleus is destroyed (Fig. 1). During the differentiation of new macronuclei (also known as anlagen), $\sim 10 \%-15 \%$ of the germline genome is eliminated by deletion of several thousand discrete internally eliminated sequences (IESs). Thus these two nuclei, both derived from the same zygotic nucleus, differ markedly in their genomic organization and sequence content.

Although several cis-acting DNA elements involved in such DNA rearrangements have been identified (Coyne et al. 1996; Wuitschick and Karrer 2003), these DNA sequences fail to explain how a heterogeneous collection of IESs are recognized and eliminated in a stagespecific fashion. Thus, it has long been suspected that epigenetic mechanisms may play a role in the general process of programmed DNA elimination. Supporting evidence was obtained when primary DNA sequences from the parental MAC were shown to dictate which sequences are eliminated in the newly forming MAC, a form of epigenetic communication that lacked a molecular explanation. This hypothesis was tested experimentally by introducing IES DNA sequences into the parental MAC (in which these sequences have already been eliminated and thus no longer exist), which resulted in inhibition of DNA elimination of the IES in the newly forming MAC (Chalker and Yao 1996).

Recently, important molecular insights have been gained into the process of DNA elimination in ciliates by demonstrating that this remarkable genomic-downsizing process is also mediated by an RNAi-like mechanism (Mochizuki et al. 2002; Yao et al. 2003; Garnier et al. 2004). Pivotal to these findings was the discovery of a remarkably abundant population of small (28-nt) RNAs specifically expressed during the conjugation pathway prior to the timing of large-scale DNA elimination (Mochizuki et al. 2002). These small RNAs were found to be enriched in micronuclear-limited sequences, and may be required for recognizing IESs in the developing macronucleus. Furthermore, an Argonaute family member, Twil, is required for DNA elimination. In Twil-deficient cells, small RNAs are detected at very low levels, suggesting a role for Twil in the generation and/or sta- 
bility of these RNAs (Mochizuki et al. 2002). An RNAibased mechanism for the process of genome-wide rearrangements was further demonstrated by the injection of dsRNA corresponding to sequences that are not normally eliminated in the MAC (Yao et al. 2003). The introduction of this RNA early in conjugation triggered efficient deletion of corresponding sequences in the newly forming MAC, suggesting that RNA may mediate the long-acknowledged communication between the old MAC and the developing new MAC (see internuclear "communication" illustrated in Fig. 2). In some ways, these studies are reminiscent of work in fission yeast where addition of a dsRNA hairpin can trigger the silencing of ectopic sequences by inciting heterochromatin assembly (Schramke and Allshire 2003).

The above data suggest that sequence elimination in ciliates occurs via an RNAi-like mechanism. Similar to RNAi-mediated silencing in fission yeast, the chromatin in which DNA elimination takes place is heterochromatic in nature, and is marked by methylated histones and enrichment in chromodomain-containing effector proteins. Interestingly, a small collection of stage-specific and actively synthesized polypeptides was identified in Tetrahymena that are collectively referred to as Pdd (Programmed DNA degradation) proteins (Madireddi et al. 1994, 1996). Pdd1 contains multiple copies of a chromodomain motif, and the other three polypeptides include Pdd2, Pdd3 (another chromodomain family member), and Twil (formerly p90) (Madireddi et al. 1994;
Smothers et al. 1997; Nikiforov et al. 1999, 2000; Y. Liu, E. Bernstein, and C.D. Allis, unpubl.). The connection between heterochromatin formation and programmed DNA elimination has been strengthened by the finding that Pdd1 and Pdd3 bind methylated Lys 9 in H3, a distinctive mark of IES elements that is observed prior to DNA elimination (Taverna et al. 2002). Interestingly, DNA to be eliminated in also marked by Lsy27 methylation (S.D. Taverna, Y. Liu, and C.D. Allis, unpubl.).

An attractive model is emerging to take into account the aforementioned data (Fig. 2). Germline IESs have been shown to be bidirectionally transcribed in micronuclei at a unique stage of the sexual pathway /Chalker and Yao 2001) and potentially give rise to the small RNAs, known as scanRNAs (scnRNAs), through processing by a Dicer-like ribonuclease (Mochizuki and Gorovsky 2005). These small RNAs would presumably be associated with Twil (or another Argonaute family member) and be escorted from the parental MAC to the new MAC. This hypothesis, known as the "scanRNA" hypothesis, is based upon the finding that Twil localizes in the cytoplasm early in conjugation, followed by its concentration in the parental MAC and finally in the new MAC (Mochizuki et al. 2002). Here, Mochizuki et al. propose that small RNAs literally "scan" the old macronuclear genome in order to determine the identity of IESs to be eliminated in the new MAC. This scan model proposes that the entire micronuclear genome or regions immediately surrounding IESs are bidirectionally tran-

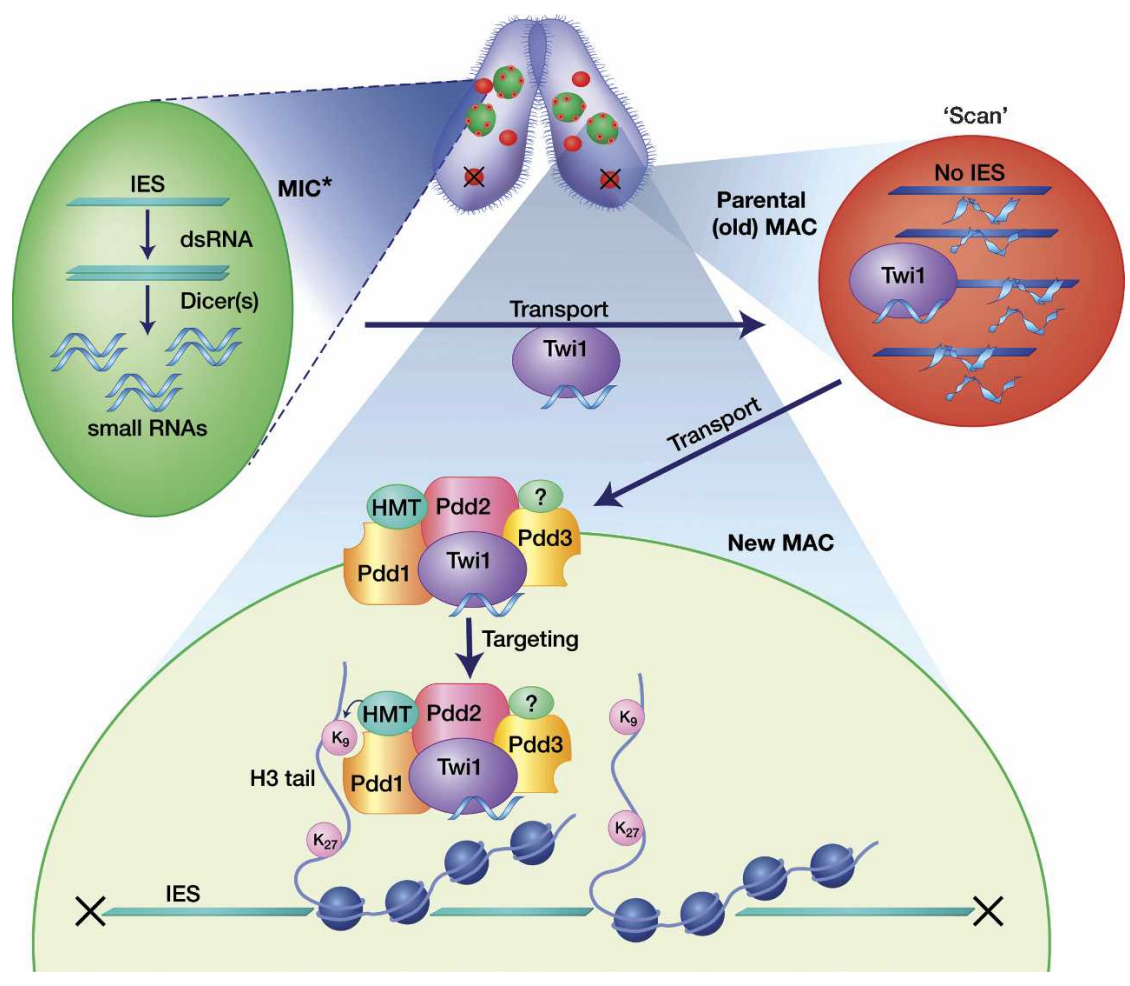

Figure 2. Tetrahymena "Scan RNA" model. The model depicted represents the "scan RNA" model put forth by Gorovsky and colleagues (Mochizuki and Gorovsky 2004). This scan model proposes that the entire micronuclear genome or regions immediately surrounding IESs are bidirectionally transcribed in the MIC. This transcription occurs prior to DNA elimination (depicted by asterisk); the MIC is active (green) for a short period when it changes morphology and elongates. During DNA elimination, the MIC resumes its silent state (shown in red in mating pair). The small (28-nt) RNAs are the products of dsRNA processing by Dicer-like ribonucleases, and are thought to be escorted by Twil from the site of dicing (presumably in the micronucleus) through the old MAC prior to its destruction (red), in which IESs have previously been eliminated. Those sequences having a homologous macronuclear DNA sequence are proposed to be degraded, while only those scnRNAs without homologous sequences in the old MAC (IESs) remain in association with Twil. These scnRNAs are then transported again (presumably in association with Twil) to the new MAC (green; active except for regions of DNA elimination, see red rings in mating pair), where they direct DNA elimination of IESs by unknown excision machinery. It is likely that Twil and associated scnRNAs interact with the Pdd proteins, two of which (Pdd1 and Pdd3) dock on H3K9me sites. Nucleosomes and histone tails are not drawn to scale. 
scribed. RNAs are thought to be escorted by Twil from the site of dicing (most likely in the micronucleus), through the old MAC, in which IES sequences have previously been eliminated. Those sequences having a homologous macronuclear DNA sequence are degraded by an unknown mechanism, while only those scnRNAs without homologous sequences in the old MAC (IESs) remain in association with Twil. These scnRNAs are then transported again (presumably in associated with Twil) to the new MAC, where they direct DNA elimination (see Fig. 2).

Although a silencing complex akin to RITS has yet to be identified in Tetrahymena, an analogous complex likely exists that contains scnRNAs, Twil, and various Pdd proteins (Fig. 2). We envision that the small RNAs, acting as the sequence-specificity determinants, would direct the relevant complexes to its IES target sites. The chromodomain-containing Pdds would recognize the heterochromatic marks, including H3 Lys 9 methylation (and perhaps other repressive histone modifications), at sequences to be eliminated (Fig. 2). It is currently unknown how chromatin-modifying enzymes are targeted to these sites, but a HMT could very well be a component of such a complex. Subsequently, unknown excision machinery (possibly similar to the RISC complex, containing a endonuclease for excision) would be recruited to eliminate these sequences from the genome. This drastic form of gene silencing in ciliates, as well as the heterochromatization of centromeres in fission yeast, demonstrates how striking the epigenetic consequences of RNAi-directed processes can be.

\section{Transcriptional gene silencing in flies}

RNA-directed silencing mechanisms have been investigated in Drosophila, including both PTGS and TGS mechanisms. For the scope of this review, we concentrate on the latter. It has been demonstrated that the introduction of repetitive transgenes in Drosophila can result in both repression of the transgene and the endogenous locus, a phenomenon known as cosuppression. Cosuppression, an RNAi-related process, occurs in many organisms including plants and fungi (for review, see Bernstein et al. 2001). Transgene cosuppression was one of the first lines of evidence to suggest the potential for RNA-directed chromatin changes in Drosophila (PalBhadra et al. 2002). In the case of white-Adh repetitive fusion transgenes, silencing is mediated by the PcG proteins, including Pc and Pc-like, as mutation of these genes relieves silencing. Furthermore, some of the PcG gene products are strongly recruited to the transgene insertion sites (Pal-Bhadra et al. 1997).

Comparable to fission yeast, mutations in the RNAi machinery also relieve heterochromatin-mediated silencing in Drosophila. Using mini-white transgene arrays and white transgenes in heterochromatic regions, Pal-Bhadra et al. (1997) demonstrated that mutations in piwi, aubergine (both Argonaute family members), and homeless cause a loss of silencing, or in other words, suppress PEV (Pal-Bhadra et al. 2004). In addition, this loss of silencing is correlated with a reduction in H3 Lys 9 methylation and delocalization of HP1 and HP2, most dramatically observed in the hls mutants. Interestingly, mutations in hls increase the expression of some retrotransposons and genomic repeats, and mutant embryos are resistant to injection of dsRNA (Aravin et al. 2001; Kennerdell et al. 2002). Although the exact molecular function of hls is unknown, its domain structure may be revealing. It contains not only a DEAD-box RNA helicase motif, but also a tudor domain. Intriguingly, tudor domains have been suggested to be a potential chromatin-binding module, as well as a potential RNA-binding motif, somewhat like the well-characterized chromodomain (Fig. 3; see below).

\section{Transcriptional gene silencing in mammals}

Transcriptional gene silencing mechanisms in mammals, analogous to those in plants and S. pombe, are still somewhat of a mystery, unlike PTGS, which has been well established in mammals. The heritable and epigenetic side of TGS is just being exposed, and mechanistic details are not yet clear. Two recent reports have suggested that gene silencing, mediated by DNA methylation, can be induced by promoter-directed siRNAs in mammalian cells (Kawasaki and Taira 2004; Morris et al. 2004). Taira and colleagues also found that siRNAs targeted to a promoter could induce $\mathrm{H} 3$ Lys 9 methylation in various mammalian cell lines (Kawasaki and Taira 2004). However, other reports have illustrated the inability to direct siRNA-induced DNA methylation. For example, siRNAs targeted to the coding region of the Huntingtin gene are not able to direct DNA methylation of the corresponding genomic locus, but are capable of reducing mRNA levels (Park et al. 2004). Another report proved unable to detect DNA methylation in mouse oocytes targeted with a 500-bp hairpin RNA (Svoboda et al. 2004b). However, the differences in experimental manipulations (i.e., targeting a promoter vs. a coding region, nuclear import of siRNAs) may be a critical factor in the outcome and interpretation of transcriptional silencing in these systems.

The requirement for RNAi in centromere silencing has been well established in fission yeast, and thus, it was hypothesized that RNAi would play a pivotal role in regulating mammalian centromeres. RNA has been implicated in the structure and maintenance of mouse pericentromeric heterochromatin (Maison et al. 2002). Evidence for RNAi-directed centromere regulation was demonstrated in chicken-human hybrid DT40 cells containing human chromosome 21, in which Dicer had been inactivated by homologous recombination (Fukagawa et al. 2004). These Dicer-deficient cells have defects in sister-chromatid cohesion, and de-repress centromeric heterochromatin, as witnessed by the accumulation of transcripts from the human satellite sequences (Fukagawa et al. 2004). Moreover, HP1 proteins were found to be partially delocalized in the nucleus, suggesting a disruption of heterochromatin by the RNAi machinery. Similar results were observed for Dicer-deficient embryonic stem 
cells (Kanellopoulou et al. 2005). Centromere-derived transcripts were up-regulated in Dicer null cells, and DNA methylation was partially abolished at the minor satellite repeats. These cells also had reduced levels of $\mathrm{H} 3$ Lys 9 methylation and diffuse staining of HP1 $\beta$ and HP1 $\gamma$. However, another report examining the loss of Dicer in ES cells discovered that transcripts derived from the centromeric major satellite accumulate, but retain the presence of cy tosine methylation (G. Hannon, pers. comm.).

Taken together, these results suggest that DNA methylation may not be the main component compromised by the loss of Dicer, but rather the loss of histone modifications such as H3 Lys 9 methylation. In support, transcription across the satellite repeats seems to be controlled, at least in part, by histone modification status. Mouse ES cells deficient in the histone methyltransferase SU/VAR/3-9 have a slight increase in the accumulation of transcripts derived from the major satellites (Lehnertz et al. 2003). Noteworthy is the fact that, thus far, centromeric small RNAs have not been identified from the many cloning studies performed in mammalian cell lines and tissues. It may be that they are in low abundance in wild-type cells; however, proving their existence will strengthen the role of RNAi-mediated chromatin regulation in mammals.

\section{Missing links: heterochromatin-associated proteins that may interact with RNA}

The RNAi machinery contains RNA-binding proteins that guide and transport RNA, such as the Argonaute family of proteins that bind small RNAs through their PAZ (piwi/argonaute/zwille) domain (Lingel et al. 2003; Song et al. 2003; Yan et al. 2003; Ma et al. 2004). However, it remains a formal possibility that chromatin-associated proteins bind RNA as well. Such interactions may help to guide and stabilize chromatin changes, by providing an additional means by which chromatin effectors can form a close association to chromatin, transcribing or otherwise. Various such chromatin-associated proteins have been implicated in RNA binding, including HP1, the chromodomains of MOF and MSL, PcG proteins, as well as others (see below). Thus, while coding RNA has had a longstanding link to actively transcribing chromatin, the use of noncoding RNA to guide chromatin regulators or to associate them more stably to chromatin, by mechanisms that remain unclear, are relatively new concepts. Here, we present a speculative model wherein these chromatin regulators may provide a direct link to RNA. In proposing this model, we acknowledge that there may be little experimental support in favor of these ideas and that other models are formally possible. In presenting these ideas, we attempt to review both supporting and opposing viewpoints. Importantly, we look forward to the next generation of experiments aimed at testing these ideas in both in vitro and in vivo settings.

\section{Chromodomain-containing proteins}

The chromodomain $(\mathrm{CD})$ was originally identified in the chromatin-associated, architectural proteins Hetero- chromatin Protein 1 (HP1) and Polycomb (Pc) of Drosophila melanogaster, leading to the proposal that they represented a conserved motif that might be involved in mediating protein:protein interactions (Paro and Hogness 1991). The chromodomain is found in a wide range of chromatin-associated proteins, mostly those involved in heterochromatin and/or transcriptional repression. These include the histone H3 Lys 9 histone methyltransferase SU(VAR)3-9 (suppressor of variegation), chromomethyltransferases (CMTs) in plants that also encode DNA methyltransferases, as well as the aforementioned HP1 and Pc proteins. However, chromodomains are also found in proteins known to be involved in transcriptional activation. These include members of the MYST family of HATs: MOF, a histone H4 Lys 16 acetyltransferase involved in dosage compensation in flies (see above), human Tip60, a transcriptional coactivator involved in DNA repair and apoptosis (Ikura et al. 2000), and Esal, a major essential histone $\mathrm{H} 4$ acetyltransferase in Saccharomyces cerevisiae with known functions in transcriptional control as well as DNA repair (Bird et al. 2002). This brief survey suggests a possible dichotomy of function for the chromodomain, or more likely, a conserved role in chromatin binding in which the outcome, either gene activation or silencing (or other), is dictated by the protein itself and those polypeptides and/or nucleic acids with which it associates.

Excellent progress has been made in demonstrating that the chromodomain is, indeed, a protein:protein interaction module, specifically by its ability to bind to methylated histone peptides. For example, the CD of HP1 has been shown to bind the histone $\mathrm{H} 3$ tail at di or trimethylated Lys 9, while interestingly, the CD of Pc has the ability to specifically bind trimethylated Lys 27 on the same histone tail despite an identical sequence immediately surrounding the target methylated lysine (Bannister et al. 2001; Jacobs et al. 2001; Lachner et al. 2001; Fischle et al. 2003b). Moreover, atomic structures of both protein-peptide complexes have been determined, which suggest a common binding fold using two features: (1) The H3 peptide itself binds by inserting itself as a missing "rung" in a $\beta$-stranded core architecture; and (2) the positively charged methyl ammonium ion is often "caged" by three highly conserved aromatic residues of the CD (Jacobs and Khorasanizadeh 2002; Nielsen et al. 2002; Min et al. 2003). However, CDs may also be more permissive in their binding capabilities. Several reports have suggested that CDs also bind to nucleic acids, both RNA and DNA (Akhtar et al. 2000; Bouazoune et al. 2002). Here, we focus our attention on potential RNA-binding properties of the chromodomain, as well as that of other chromatin-associated proteins.

\section{The CDs of the Drosophila DCC}

As previously mentioned, the dosage compensation complex of Drosophila contains roX RNAs as well as two CD-containing proteins, MOF and MSL. These proteins were shown to interact with the $\mathrm{X}$ chromosome in an RNase-sensitive manner and to bind RNA in vitro 
(Akhtar et al. 2000). RNase treatment of Drosophila S2 cells resulted in loss of MOF staining on the X chromosome, and electromobility shift assays revealed an intriguing interaction between MOF and RNA. A mutation in one of the caging aromatic residues of the MOF chromodomain resulted in a loss of RNA binding, suggesting that these residues may also be important for nucleic acid binding (Akhtar et al. 2000). Although it has since been shown that MOF CD interaction with the roX RNAs plays only a minor role in targeting it to the $\mathrm{X}$ chromosome in vivo, the MOF CD:RNA interaction still potentially contributes to its localization (Morales et al. 2004). Further support for the ability of CDs to bind nucleic acids comes from the Esal HAT in yeast. The chromodomain of this protein is essential for viability, and binds nucleic acids with an affinity for RNA over DNA. Interestingly, this RNA binding stimulates Esa1 HAT activity in vitro (J. Smith, pers. comm.). It should also be noted that the third CD of Pdd1, involved in DNA elimination in Tetrahymena, has also been hypothesized to be an RNA-binding domain based on structural comparisons to nucleic acid-binding proteins (Taverna et al. 2002). Additional analysis of the chromodomain likely will prove essential to provide a more mechanistic and structural basis for how these modules interact with RNA (see Fig. 3).

\section{HP1 and RNA in the maintenance of pericentric heterochromatin}

Heterochromatin in mouse pericentromeric regions has an RNA component that is required for its integrity, the nature of which is still unknown. For example, RNase treatment of mouse fibroblasts results in delocalization of HP1 $\alpha$ from the pericentric heterochromatin and prevents detection of the normal foci seen by H3 Lys 9 methyl-specific antibodies (Maison et al. 2002). As previously mentioned, HP1 is a hallmark property of constitutive heterochromatin and is the effector-binding partner of $\mathrm{H} 3$ methylated at Lys 9. Surprisingly, following RNase treatment of cells, the addition of total RNA from mouse fibroblasts, but not from bacteria, rescued the observed localization defects. These findings suggest that a currently unknown component in the total pool of RNA (possibly small RNAs) is required to target heterochromatin formation at pericentric regions. In support, association of $\mathrm{HP} 1 \alpha$ at pericentric regions is dependent not only on its histone methyl-lysine-binding ability, but also on RNA binding (Muchardt et al. 2002).

$\mathrm{HP} 1$ isoforms contain an N-terminal CD; however, the RNA-binding activity of $\mathrm{HP} 1 \alpha$ appears to be in the hinge region of the protein, a region that links the chromodomain with the chromoshadow domain. The hinge region of $\mathrm{HP} 1$ is rich in basic residues, and although this region displays no obvious homology to RNA-binding proteins, these "basic patches" are found in several ribosomal proteins (Muchardt et al. 2002). Although the basic patches may bind RNA nonspecifically, they may represent a new kind of RNA-binding domain. It will be of interest to determine if motifs of this type exist in other chromatin-associated proteins.

One intriguing possibility is that CD-containing proteins may recognize and bind to their target sites in chromatin through multiple interactions (Fig. 3). For example, the stable interaction of HP1 to chromatin may require not only methylation of $\mathrm{H} 3$ at Lys 9, but also an interaction with an unidentified RNA (or other) component(s). The extent to which this occurs in other CDcontaining proteins, for example, Polycomb, is not known. However, the possibility that synergistic interactions between a protein or a complex of proteins and its various substrates in order to enhance its binding affinity for chromatin, is an interesting one. Simultaneous chromatin and nucleic acid binding may be required in order to regulate gene expression appropriately. We envision that this may occur in several ways: (1) A protein complex may contain a particular polypeptide required for chromatin binding and another for targeting the complex to a specific locus by an RNA-guided interaction (e.g., RITS or possibly the DCC in flies) (see Fig. 3); (2) a single polypeptide may contain both a chromatin-binding domain and an RNA-binding domain (HP1); and (3) a single domain within a single polypeptide may perform both of these functions, possibly to enhance its binding affinity and specificity-for example, a chromodomain (see Fig. 3A,B).

Experimental evidence in support of scenarios 2 and 3 is perhaps limited. Defined regions of chromatin may be marked by RNA acting as signal posts at specific locations in the genome, or alternatively, CD-containing complexes may be preloaded with RNAs that determine the specificity for target sites. The RITS complex in fission yeast contains small RNAs bound by Agol (Verdel et al. 2004) and, interestingly, also contains a CD-containing protein Chp1. Although to our knowledge, it not known whether Chp1 interacts with small RNAs in the complex, directly or indirectly, to enhance its binding affinity for methylated Lys 9 in H3 (see Fig. 3). Chromomethyltransferases are DNA methyltransferases that also contain a chromodomain, a unique combination of domains found particularly in plants. Interestingly, the chromodomain of CMT3 can directly interact with the $\mathrm{N}$-terminal tail of histone $\mathrm{H} 3$, but only when it is simultaneously methylated at both Lys 9 and Lys 27 positions in H3 (Lindroth et al. 2004). It is intriguing to speculate that the chromodomain of these plant-specific proteins may also bind RNA directly, or in combination with other RNA-binding partners, to direct sequence-specific DNA methylation, resulting in TGS.

\section{Other chromatin-associated proteins that interact with RNA}

Although it is not understood how RNA affects overall chromatin organization, various chromatin-associated proteins bind to RNA. For example, although an RNAdependent step in Hox gene repression by PcG proteins has been suggested (Grewal and Moazed 2003), until recently, RNA binding by these proteins had not been di- 


\section{A}

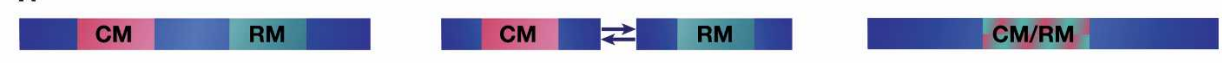

B

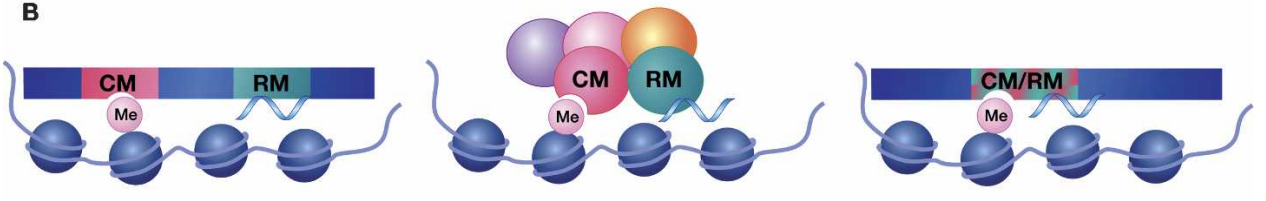

c

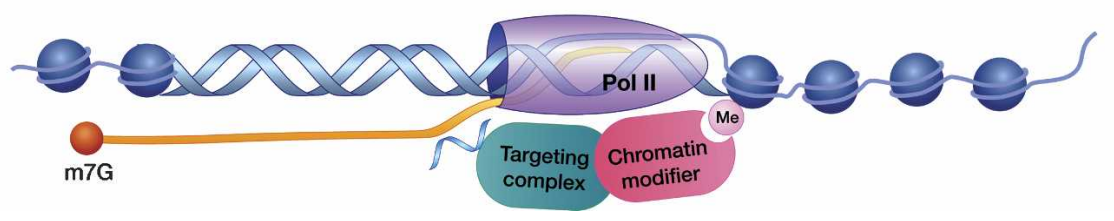

Figure 3. Models for coordinated RNA and chromatin binding. Multiple combinations of chromatin modules (CM) and RNA modules (RM) may exist in polypeptides in order to mediate chromatin structure. (A) CMs and RMs can exist as separate domains or regions of the same polypeptide (e.g., HP1), in two different polypeptides within a complex of proteins (e.g., chp1 and agol of RITS) or even potentially in the very same domain. This last possibility is intriguing as various chromatin modules have also been shown to interact with nucleic acids, including chromodomains and tudor domains (see text for details). The ability to interact with both entities may enhance a protein's binding affinity and specificity for its substrate. $(B)$ The polypeptides described above interacting with nucleosomes (not drawn to scale). A methyl group on a histone tail is shown as a potential substrate for CM binding, as it is well characterized to be mediated by RNAi phenomena; however, other modifications may be regulated in a similar fashion. (C) RNAi-mediated chromatin assembly may be directed by a multicomponent complex that includes a chromatin modifier, which docks on a specific histone modification, and a targeting complex that contains small RNAs. This targeting may occur by RNA:DNA interactions or RNA:RNA interactions. Illustrated here is the latter; the interaction of a targeting complex with a nascent transcript produced by RNA polymerase II (Pol II). This model is representative of RITS and RDRC, which localize to noncoding centromeric transcripts. The ability of a complex to interact with both RNA and modified histones represents a potential mechanism to enhance its affinity for a particular locus.

rectly demonstrated. Supporting evidence for this hypothesis comes from the C. elegans homolog of mammalian Polyhomeotic 1 (also known as Rae28), sop-2, that displays RNA-binding activity (Zhang et al. 2004). Interestingly, Polyhomeotic 1 was one of the PRC1 components recently shown to bind the inactive $\mathrm{X}$ chromosome (Plath et al. 2004; see above), and to have affinity for RNA (Zhang et al. 2004). Three unique regions of SOP-2 bind RNA and are essential for its localization to characteristic nuclear speckles (PcG bodies). Moreover, SOP-2 protein lacking any of these RNA-binding regions fails to rescue homeotic transformations in sop-2 mutant worms. These RNA-binding regions do not represent any known domains, but rather are highly charged or basic like the hinge region of HP1. These findings suggest a conserved role for PcG proteins and may imply that RNA plays an important role in Hox gene regulation.

The DDP1 (Drosophila dodeca centromeric-binding protein) protein of Drosophila contains 15 tandem KH domains, which are high-affinity RNA- and ssDNAbinding motifs. Multi-KH domain proteins are known to act in various aspects of RNA metabolism (Birchler et al. 2004). DDP1, as its name implies, is found in association with the chromocenter (HP1-containing heterochromatin) in polytene chromosomes (see Fig. 1). In a recent study, the mutant $d d p 1$ allele was found to behave as a suppressor of PEV, suggesting strongly that the wild-type protein functions positively for silencing (Huertas et al. 2004). Furthermore, polytene chromosomes of $d d p 1 \mathrm{mu}-$ tant larvae display a striking reduction of H3 Lys 9 methylation and HP1 localization at the chromocenter. It is appealing to speculate that DDP1 might guide small RNAs to facilitate heterochromatin formation or, like $\mathrm{HP1}$, play a role in maintaining the structure of heterochromatin in an RNA-dependent fashion (Huertas et al. 2004).

\section{Intriguing links between RNA and chromatin}

\section{The histone variant macroH2A}

In mammals, macroH2A (mH2A) is preferentially concentrated on the inactive $\mathrm{X}$ chromosome in females, suggestive of a role in transcriptionally repressed chromatin (Pehrson and Fried 1992). MacroH2A is an unusually large $\mathrm{H} 2 \mathrm{~A}$ variant that contain an $\mathrm{N}$-terminal $\mathrm{H} 2 \mathrm{~A}$ region $(-65 \%$ identity to core histone $\mathrm{H} 2 \mathrm{~A})$ and a large C-terminal nonhistone region, the "macro domain" (Pehrson and Fried 1992). Separate genes encode two isoforms of mH2A, mH2A1 and mH2A2, and both localize to the Xi. However, mH2A1.2, a splice variant of mH2A1, is the most abundant isoform on the Xi. Although the precise role of $\mathrm{mH} 2 \mathrm{~A}$ in $\mathrm{X}$ inactivation has yet to be determined, its dependence on the expression of 
the Xist RNA suggests a role in maintaining the silenced state of the $\mathrm{Xi}$, possibly through an RNA-binding mechanism. mH2A has been shown to localize to the $\mathrm{Xi}$ in an Xist-dependent manner even though its incorporation on the Xi occurs somewhat late in the inactivation process (Csankovszki et al. 1999).

Interestingly, the macro domain is found in all organisms and can be found either to comprise an entire protein on its own (in bacteria, archaea, and eukaryotes) or may represent a domain that is part of a larger protein (as with $\mathrm{mH} 2 \mathrm{~A}$ ). The wide distribution of this domain suggests a conserved and important function. Macro domains are also found in the nonstructural proteins of several types of ssRNA viruses, for example, rubella and corona viruses (Allen et al. 2003). In the case of $\mathrm{mH} 2 \mathrm{~A}$, the macro domain has been precisely fused onto the end of the histone $\mathrm{H} 2 \mathrm{~A}$, possibly as a means to deposit this domain into chromatin. Several potential roles have been put forth for the macro domain, including an enzymatic activity that regulates ADP-ribosylation and an RNA-binding motif (Ladurner 2003). The crystal structure of a macro domain from the thermophile Archaeoglobus fulgidus has been solved. Interestingly, the structure revealed homology to the P-loop family of nucleotide hydrolases and is also similar to a DNA-binding domain of Escherichia coli, suggesting a potential for nucleic acid interactions (Allen et al. 2003). However, Ladurner and colleagues have recently demonstrated that macro domains are high-affinity ADP-ribose-binding modules (Karras et al. 2005). Although a role for the macro domain has now been established, all macro domains might not be conserved in function, particularly the three $\mathrm{mH} 2 \mathrm{~A}$ isoforms. Thus, it is tempting to speculate that because $\mathrm{mH} 2 \mathrm{~A}$ is found to associate with the RNA-coated, inactive $\mathrm{X}$ chromosome, a role in RNA binding or another aspect of RNA metabolism, remains possible.

\section{Tudor domains}

Although the role of chromatin-associated proteins in binding RNA is not fully understood, it seems likely, if not certain, that RNA-binding proteins contribute to heterochromatin formation. For example, the tudor gene product of Drosophila contains multiple repetitive domains now referred to as the tudor domain (Golumbeski et al. 1991). The tudor protein is a posterior-group gene product required for proper development of the fly embryo and its germline. The tudor domain is also found in the homeless gene product (also known as spindle E), discussed above, which contains a DEAH-box RNA helicase domain. Homeless is required for RNA localization during embryogenesis (Gillespie and Berg 1995), and has recently been shown to be important for RNAi-dependent heterochromatin formation in flies (Pal-Bhadra et al. 2004). Mutations of homeless in flies results in dramatic effects on the localization of HP1 in polytene chromosomes as well as a decrease in H3 Lys 9 methylation. In addition, the tudor domain appears in TSN1, a protein that contains five staphylococcal/micrococcal nuclease domains, and is a component of the RISC complex involved in RNAi (Caudy et al. 2003).

Interestingly, the tudor domain has been compared by sequence and structural methods to the chromodomain, PWWP (proline and tryptophan), and MBT (malignant brain tumor) domains, and a newly identified plant-specific domain named the "agenet" domain (Maurer-Stroh et al. 2003). This study found that the three- $\beta$-stranded core, common to all of these domains, originates from a common ancestor. Although, the exact function of the tudor domain is not known, its substrates have been examined. The tudor domain of SMN (survival of motor neuron; linked to spinal muscular atrophy) has been shown to bind symmetrically dimethylated arginines of the RG-rich Sm proteins that are involved in spliceosomal complexes (Selenko et al. 2001; Sprangers et al. 2003); and that of p53-binding protein 1 (p53BP1) has been reported to have an affinity for DNA and RG-rich protein sequences (Charier et al. 2004). Tudor-domaincontaining proteins are also implicated in RNA regulation (RNAi, splicing, mRNA transport in Drosophila development). Thus, it seems entirely plausible that this domain, as well as those that are better understood such as chromodomains (see above), may have dual binding properties-a specificity for nucleic acids and a specificity for appropriately modified amino acids (e.g., methyllysine in histone peptides). For example, in the case of homeless, the tudor domain may bind RNA, and use the domain to target other proteins, such as modified histones (see Fig. 3).

\section{PcG proteins}

Recruitment of the PcG proteins to their target loci in Drosophila is in part regulated by DNA-binding proteins and the DNA elements, known as Polycomb response element (PREs), to which they bind (Ringrose and Paro 2004). However, in other systems, no such conserved elements have yet to be identified. Thus, it remains a formal possibility that RNA may regulate PcG targeting through an RNAi-based mechanism. Evidence for this hypothesis is supported by the discovery of genetic interactions between PcG mutants and the RNAi machinery in C. elegans (see below) and Drosophila (above), as well as the aforementioned RNA-binding affinity of Polyhomeotic proteins.

Since its discovery, numerous screens have been performed in C. elegans in order to identify genes involved in RNAi. Many novel genes have been characterized including those with enzymatic activities (Ago, RdRP), RNA-binding molecules, and those that regulate transposon mobilization. However, none of these gene products seems to be involved in TGS-like mechanisms, such as chromatin regulation. Nevertheless, it appears that three of the C. elegans mes (maternal effect sterile) genes, which participate in silencing the $\mathrm{X}$ chromosome of the hermaphrodite germline and encode homologs of the Polycomb group proteins, are involved in RNAi (Dudley et al. 2002). These consist of mes3, mes4, and mes6. MES6 encodes a homolog of Extra sex combs (ESC, 
also known as EED in mammals) and is the counterpart of $E(z)$, the H3 Lys 27 HMT (MES2), which was not found to be important for RNAi in this study. MES3 is a novel protein with no recognizable motifs, and MES4 is similar to MES2 in that it encodes an HMT, but its histone substrate specificity is unknown and it is not part of the MES complex that contains MES2, MES3, and MES6 (Bender et al. 2004).

The above proteins seem to be required for RNAi under some, but not all, conditions tested (low concentrations of dsRNA can bypass a requirement for these genes in RNAi). It is nonetheless interesting to consider that transcriptional gene silencing may be occurring through an RNA-directed mechanism in the C. elegans germline. Although DNA methylation in the C. elegans genome has yet to be detected, altered chromatin structures have been implicated in transgene cosuppression in this organism, and this silencing is mediated, in part, by the mes genes (Kelly and Fire 1998). Remarkably, a recent study in C. elegans aimed at cataloging genes required for cosuppression in the germline has identified factors required for chromatin remodeling, including a CD-containing protein and MES4, in addition to factors known to be involved in RNAi (Robert et al. 2005). Interestingly, although cosuppression has been observed mainly in the germline, it is also present to a limited extent in somatic tissues (Dernburg et al. 2000). Recently, a TGS mechanism has been demonstrated to be important for somatic transgene silencing in the worm that is dependent on the Argonaute family member alg-1 and the HP1 homolog hpl-2 (Grishok et al. 2005). In total, it appears that the lines of RNA and chromatin-mediated events are, indeed, beginning to blur.

\section{miRNAs and chromatin}

microRNAs now claim hundreds of members in worms, flies, plants, and mammals. These RNAs have diverse expression patterns and regulate many aspects of development (see above), and as already stressed in this review, many chromatin-associated proteins also regulate development, for example, the PcG genes. It is intriguing to speculate that miRNAs may regulate the expression of key chromatin regulators. In support, a recent study predicting miRNA target genes in humans has listed various histone methyltransferases, methyl CpG-binding proteins, CD-containing proteins, and histone deacetylases (Lewis et al. 2005). Moreover, a recent study in C. elegans identified let- 7 target genes by a combination of sequence analysis and genetics; one of these is a predicted chromatin-remodeling factor (Grosshans et al. 2005). Besides their role in targeting genes for translational inhibition or mRNA destruction, it also appears that certain miRNAs in plants can direct DNA methylation of their target genes (Bao et al. 2004). It remains a challenge for future studies to determine whether chromatin modifications can be brought about by similar mechanisms.

\section{Unanswered questions and future directions}

While the link is still blurred, it appears that RNA can act in a concerted fashion to orchestrate changes in higher-order chromatin structures. Here we have described the ways in which RNA molecules affect chromatin structure in various cellular pathways, mainly those involved in transcriptional gene silencing. It is evident that the worlds of RNA and chromatin are, indeed, colliding. An increasing number of chromatin-associated proteins have been implicated in RNA binding, including heterochromatin and silencing-related proteins HP1 and PcG family members. Although there is increasing evidence to support the notion that epigenetic effects are RNA-directed, many outstanding questions remain.

For example, in the process of dosage compensation in mammals, the transcription of the Tsix gene, antisense to Xist, begs the question of how it regulates Xist transcription. As mentioned earlier, Xist up-regulation on the future Xi coincides with the transcriptional repression of Tsix. These sense and antisense transcripts are candidates for the formation of double-stranded RNA that may either mask domains required for the recruitment of trans-acting factors or, alternatively, trigger the RNAi machinery (Morey and Avner 2004). The latter may lead to a TGS-like mechanism that results in $\mathrm{H} 3$ Lys 9 methylation and subsequent chromatin changes. This would be akin to the RNAi-mediated chromatin regulation recently discovered in fission yeast. However, an important piece of the puzzle is missing - the identification of small RNAs corresponding to Xist and its partner Tsix.

Given the differences between the dosage compensation mechanisms of flies and mammals, it is worth noting that many of the MSL proteins of the Drosophila DCC are conserved in mammals. Although almost certainly not involved in dosage compensation in mammals, these subunits are likely to have evolved a function(s) that involves transcriptional up-regulation. It will be of interest to determine the role of these proteins in mammals and to identify the noncoding RNAs, if any, that are an integral part of this novel RNP chromatinmodifying complex.

As previously discussed, the MES system in C. elegans participates in silencing the $\mathrm{X}$ chromosomes in the hermaphrodite germline, and the loss of these proteins leads to germline degeneration and sterility. This requirement of the MES PcG proteins in germline silencing in C. elegans appears to be extremely similar to X-chromosome silencing in mammals, which involves the orthologous PcG proteins. One then has to wonder if an RNA component, such as a noncoding RNA like Xist, plays a role in silencing the $\mathrm{X}$ chromosome in the C. elegans germline. Furthermore, since the MES family of proteins is important for RNAi and cosuppression in the germline, does X-chromosome silencing in C. elegans involve RNAi?

In thinking about these steps of mammalian $\mathrm{X}$ inactivation, it is instructive to recognize that the "memory" of gene activation versus gene silencing is also a feature of other epigenetic regulatory processes such as the regulation of HOX genes in mammals by epigenetic marks. These include activating (Lys 4 in H3) or inactivating (Lys 27 in H3) histone methylation marks placed by the 
HMTases, MLL versus EzH2, respectively (Francis and Kingston 2001). Interestingly, noncoding RNAs have been reported to be transcribed through the PREs in Drosophila (Ringrose and Paro 2004). Whether or not these noncoding RNAs are intimately linked to Hox gene regulation is not known, but remains an intriguing possibility.

Evidence discussed throughout this review suggests that RNA can act as a recruiting entity, a scaffolding factor, or a sequence-specificity determinant involved in targeting histone modifications (see Fig. 3). Dosage compensation in both flies and mammals requires long, noncoding RNAs, which spread in cis to "coat" the X chromosome. The regions of the 17-kb-long Xist RNA that are required for localization on the $\mathrm{Xi}$ have no obvious sequence homology (Wutz et al. 2002). This also holds true in the case of the roX RNAs, which contain little sequence homology to one another, except for a stretch of $30 \mathrm{nt}$, the function of which is unknown (Meller and Rattner 2002). The lack of sequence homology required for interactions with chromatin-remodeling machinery, may point toward a common molecular feature for RNA action. It seems likely that these RNAs serve as strong recruiting entities or scaffolding factors for cooperative binding of chromatin-associated complexes. It should be noted that although the Drosophila DCC is well characterized with its structural RNAs and protein counterparts, whether or not an analogous RNP complex forms with the Xist RNA in mammalian $\mathrm{X}$ inactivation remains unknown, but is an area of active research.

Noncoding RNAs also serve as "guide" molecules that serve to direct protein complexes to specific transcripts or genomic loci, such as the centromere. This phenomenon is well-characterized in the case of RNAi complexes such as (1) RISC, which uses siRNAs to target destruction of its cognate mRNA; and (2) RITS, a CDcontaining complex that remarkably docks on a site-specific histone modification, and is presumably guided by the siRNAs that it carries in order to maintain the heterochromatic state of its target locus. It currently unknown whether chromatin-modifying enzymes, such as histone methyltransferases (e.g., Clr4 in fission yeast), also function in the establishment of heterochromatin through the interaction of small guiding RNAs.

This review discusses the ways in which heterochromatin assembly is broadly used to silence or eliminate DNA segments by an emerging paradigm that involves the production of small RNAs, generation of histone methylation marks, and the docking of effector proteins that often use chromodomains to "read" the relevant methyl marks. While attractive, little mechanistic information is currently available to appreciate the actual role(s) of RNAs in the above pathway. For example, how does RNA guide histone-modifying activities to genomic loci where they are needed to write their marks? Do effector proteins bind their respective modified residues solely based on covalent modification marks? Or is there a reinforcing entity, such as RNA, by which these marks are placed and read by effectors or conceivably other proteins in an effector complex (Fig. 3)? If transcription is required to initiate the above epigenetic silencing events, we wonder if epigenetic silencing is reversible, and if so, how? For example, while chromodomains or chromodomain-like modules are accepted to be contextdependent, methyl-lysine-binding motifs, it remains unclear the extent to which methylated RNA might also be a target-binding surface. Methylated RNA, such as cap structures, might provide an attractive means to "anchor" chromatin-modifying complexes to transcribed loci. Other potential interactions might include other transcription markers, such as pol II itself (see Fig. 3C). One central problem that has yet to be critically addressed is how epigenetic marks are templated during DNA replication and faithfully inherited during cell division. If, indeed, RNA serves to guide epigenetic marks, how is this propagated? Resolving the biology underlying how RNA mediates such an array of circumstances within the cell is imperative in order to bring us one step closer to decoding epigenetic processes.

\section{Summary}

In closing, we underscore that RNA and chromatin are closely intertwined in a remarkably large number of biological systems, only some of which have been discussed here. We favor the general view that chromatin-associated remodeling enzymes and binding effector proteins take some of their cues from RNA-directed mechanisms. Exactly what these cues are and how the RNA "talks" to chromatin to bring about altered epigenetic states are not known. We look forward to future experiments aimed to test the general hypothesis that chromatin-associated proteins directly interact with RNA, and what the true meaning of these interactions is. Answers to these questions promise to keep researchers captivated for many years to come.

\section{Acknowledgments}

We thank Elizabeth Duncan, Edwin Smith, and Jason Tanny for suggestions and comments on this manuscript. We are greatly appreciative to Sue Ann Fung-Ho for assistance with figures. We apologize to those whose work was not cited due to space restrictions. This work was funded by the National Science Foundation (E.B.) and research grants from the NIH to C.D.A. (GM53512 and GM63959).

\section{References}

Akhtar, A., Zink, D., and Becker, P.B. 2000. Chromodomains are protein-RNA interaction modules. Nature 407: 405-409.

Allen, M.D., Buckle, A.M., Cordell, S.C., Lowe, J., and Bycroft, M. 2003. The crystal structure of AF1521 a protein from Archaeoglobus fulgidus with homology to the non-histone domain of macroH2A. J. Mol. Biol. 330: 503-511.

Allshire, R.C., Nimmo, E.R., Ekwall, K., Javerzat, J.P., and Cranston, G. 1995. Mutations derepressing silent centromeric domains in fission yeast disrupt chromosome segregation. Genes \& Dev. 9: 218-233.

Aravin, A.A., Naumova, N.M., Tulin, A.V., Vagin, V.V., Rozovsky, Y.M., and Gvozdev, V.A. 2001. Double-stranded 
RNA-mediated silencing of genomic tandem repeats and transposable elements in the D. melanogaster germline. Curr. Biol. 11: 1017-1027.

Aravin, A.A., Lagos-Quintana, M., Yalcin, A., Zavolan, M., Marks, D., Snyder, B., Gaasterland, T., Meyer, J., and Tuschl, T. 2003. The small RNA profile during Drosophila melanogaster development. Dev. Cell 5: 337-350.

Avner, P. and Heard, E. 2001. X-chromosome inactivation: Counting, choice and initiation. Nat. Rev. Genet. 2: 59-67.

Bannister, A.J., Zegerman, P., Partridge, J.F., Miska, E.A., Thomas, J.O., Allshire, R.C., and Kouzarides, T. 2001. Selective recognition of methylated lysine 9 on histone $\mathrm{H} 3$ by the HP1 chromo domain. Nature 410: 120-124.

Bao, N., Lye, K.W., and Barton, M.K. 2004. MicroRNA binding sites in Arabidopsis class III HD-ZIP mRNAs are required for methylation of the template chromosome. Dev. Cell 7: 653-662.

Bender, L.B., Cao, R., Zhang, Y., and Strome, S. 2004. The MES2/MES3/MES6 complex and regulation of histone H3 methylation in C. elegans. Curr. Biol. 14: 1639-1643.

Bernstein, E., Denli, A.M., and Hannon, G.J. 2001. The rest is silence. RNA 11: 1509-1521.

Birchler J.A., Kavi, H.H., and Fernandez, H.R. 2004. Heterochromatin: RNA points the way. Curr. Biol. 14: R759-R761.

Bird, A.W., Yu, D.Y., Pray-Grant, M.G., Qiu, Q., Harmon, K.E., Megee, P.C., Grant, P.A., Smith, M.M., and Christman M.F. 2002. Acetylation of histone $\mathrm{H} 4$ by Esal is required for DNA double-strand break repair. Nature 419: 411-415.

Boggs, B.A., Cheung, P., Heard, E., Spector, D.L., Chinault, A.C., and Allis, C.D. 2002. Differentially methylated forms of histone $\mathrm{H} 3$ show unique association patterns with inactive human X chromosomes. Nat. Genet. 30: 73-76.

Bouazoune, K., Mitterweger, A., Langst, G., Imhof, A., Akhtar, A., Becker, P.B., and Brehm, A. 2002. The dMi-2 chromodomains are DNA binding modules important for ATP-dependent nucleosome mobilization. EMBO J. 21: 2430-2440.

Brennecke, J., Hipfner, D.R., Stark, A., Russell, R.B., and Cohen, S.M. 2003. Bantam encodes a developmentally regulated microRNA that controls cell proliferation and regulates the proapoptotic gene hid in Drosophila. Cell 113: 25-36.

Carmell, M.A. and Hannon, G.J. 2004. RNase III enzymes and the initiation of gene silencing. Nat. Struct. Mol. Biol. 11: 214-218.

Carmen, A.A., Milne, L., and Grunstein, M. 2002. Acetylation of the yeast histone $\mathrm{H} 4 \mathrm{~N}$ terminus regulates its binding to heterochromatin protein SIR3. I. Biol. Chem. 277: 47784781 .

Caudy, A.A., Ketting, R.F., Hammond, S.M., Denli, A.M., Bathoorn, A.M., Tops, B.B., Silva, J.M., Myers, M.M., Hannon, G.J., and Plasterk, R.H.A. 2003. A micrococcal nuclease homologue in RNAi effector complexes. Nature 425: 411-414.

Chalker, D.L. and Yao, M.C. 1996. Non-Mendelian, heritable blocks to DNA rearrangement are induced by loading the somatic nucleus of Tetrahymena thermophila with germ line-limited DNA. Mol. Cell Biol. 16: 3658-3667.

- 2001. Nongenic, bidirectional transcription precedes and may promote developmental DNA deletion in Tetrahymena thermophila. Genes \& Dev. 15: 1287-1298.

Charier, G., Couprie, J., Alpha-Bazin, B., Meyer, V., Quemeneur, E., Guerois, R., Callebaut, I., Gilquin, B., and Zinn-Justin, S. 2004. The Tudor tandem of 53BP1: A new structural motif involved in DNA and RG-rich peptide binding. Structure 12: $1551-1562$.

Cogoni, C. and Macino, G. 1999. Posttranscriptional gene silencing in Neurospora by a RecQ DNA helicase. Science 286: $2342-2344$.
Cosgrove, M.S., Boeke, J.D., and Wolberger, C. 2004. Regulated nucleosome mobility and the histone code. Nat. Struct. Mol. Biol. 11: 1037-1043.

Coyne, R.S., Chalker, D.L., and Yao, M.C. 1996. Genome downsizing during ciliate development: Nuclear division of labor through chromosome restructuring. Annu. Rev. Genet. 30: 557-578.

Csankovszki, G., Panning, B., Bates, B., Pehrson, J.R., and Jaenisch, R. 1999. Conditional deletion of Xist disrupts histone macroH2A localization but not maintenance of $\mathrm{X}$ inactivation. Nat. Genet. 22: 323-324.

Csink, A.K. and Henikoff, S. 1998. Something from nothing: The evolution and utility of satellite repeats. Trends Genet. 14: 200-204.

Cullen, B.R. 2004. Transcription and processing of human microRNA precursors. Mol. Cell 16: 861-865.

Cuthbert, G.L., Daujat, S., Snowden, A.W., Erdjument-Bromage, H., Hagiwara, T., Yamada, M., Schneider, R., Gregory, P.D., Tempst, P., Bannister, A.J., et al. 2004. Histone deimination antagonizes arginine methylation. Cell 118: 545-553.

Dernburg, A.F., Zalevsky, J., Colaiacovo, M.P., and Villeneuve, A.M. 2000. Transgene-mediated cosuppression in the C. elegans germ line. Genes \& Dev. 14: 1578-1583.

Dudley, N.R., Labbe, J.C., and Goldstein, B. 2002. Using RNA interference to identify genes required for RNA interference. Proc. Natl. Acad. Sci. 99: 4191-4196.

Ekwall, K., Javerzat, J.P., Lorentz, A., Schmidt, H., Cranston, G., and Allshire, R. 1995. The chromodomain protein Swi6: A key component at fission yeast centromeres. Science 269: 1429-1431.

Ekwall, K., Nimmo, E.R., Javerzat, J.P., Borgstrom, B., Egel, R., Cranston, G., and Allshire, R. 1996. Mutations in the fission yeast silencing factors clr4 and rik1 disrupt the localisation of the chromo domain protein Swi6p and impair centromere function. J. Cell Sci. 109: 2637-2648.

Ekwall, K., Cranston, G., and Allshire, R.C. 1999. Fission yeast mutants that alleviate transcriptional silencing in centromeric flanking repeats and disrupt chromosome segregation. Genetics 153: 1153-1169.

Elgin, S.C. and Grewal, S.I. 2003. Heterochromatin: Silence is golden. Curr. Biol. 13: R895-R898.

Filippova, G.N., Cheng, M.K., Moore, J.M., Truong, J.P., Hu, Y.J., Nguyen, D.K., Tsuchiya, K.D., and Disteche, C.M. 2005. Boundaries between chromosomal domains of X inactivation and escape bind CTCF and lack CpG methylation during early development. Dev. Cell 8: 31-42.

Fire, A., Xu, S., Montgomery, M.K., Kostas, S.A., Driver, S.E., and Mello, C.C. 1998. Potent and specific genetic interference by double-stranded RNA in Caenorhabditis elegans. Nature 391: 806-811.

Fischle, W., Wang, J., and Allis, C.D. 2003a. Binary switches and modification cassettes-Novel concepts in histone biology and beyond. Nature 425: 475-479.

Fischle, W., Wang, Y., Jacobs, S.A., Kim, Y., Allis, C.D., and Khorasanizadeh, S. 2003b. Molecular basis for the discrimination of repressive methyl-lysine marks in histone $\mathrm{H} 3$ by Polycomb and HP1 chromodomains. Genes \& Dev. 17: 1870-1881.

Francis, N.J. and Kingston, R.E. 2001. Mechanisms of transcriptional memory. Nat. Rev. Mol. Cell Biol. 2: 409-421.

Fukagawa, T., Nogami, M., Yoshikawa, M., Ikeno, M., Okazaki, T., Takami, Y., Nakayama, T., and Oshimura, M. 2004. Dicer is essential for formation of the heterochromatin structure in vertebrate cells. Nat. Cell Biol. 6: 784-791.

Garnier, O., Serrano, V., Duharcourt, S., and Meyer, E. 2004. RNA-mediated programming of developmental genome re- 
arrangements in Paramecium tetraurelia. Mol. Cell Biol. 24: 7370-7379.

Gendrel, A.V. and Colot, V. 2005. Arabidopsis epigenetics: When RNA meets chromatin. Curr. Opin. Plant Biol. 8: $142-147$.

Gilfillan, G.D., Dahlsveen, I.K., and Becker, P.B. 2004. Lifting a chromosome: Dosage compensation in Drosophila melanogaster. FEBS Lett. 567: 8-14.

Gillespie, D.E. and Berg, C.A. 1995. Homeless is required for RNA localization in Drosophila oogenesis and encodes a new member of the DE-H family of RNA-dependent ATPases. Genes \& Dev. 9: 2495-2508.

Golumbeski, G.S., Bardsley, A., Tax, F., and Boswell, R.E. 1991. Tudor, a posterior-group gene of Drosophila melanogaster, encodes a novel protein and an mRNA localized during midoogenesis. Genes \& Dev. 5: 2060-2070.

Goodfellow, P.J., Mondello, C., Darling, S.M., Pym, B., Little, P., and Goodfellow, P.N. 1988. Absence of methylation of a CpG-rich region at the $5^{\prime}$ end of the MIC2 gene on the active $\mathrm{X}$, the inactive $\mathrm{X}$, and the $\mathrm{Y}$ chromosome. Proc. Natl. Acad. Sci. 85: 5605-5609.

Goto, Y., Gomez, M., Brockdorff, N., and Feil, R. 2002. Differential patterns of histone methylation and acetylation distinguish active and repressed alleles at X-linked genes. Cytogenet. Genome Res. 99: 66-74.

Grewal, S.I. and Moazed, D. 2003. Heterochromatin and epigenetic control of gene expression. Science 301: 798-802.

Grishok, A., Sinskey, J.L., and Sharp, P.A. 2005. Transcriptional silencing of a transgene by RNAi in the soma of C. elegans. Genes \& Dev. 19: 683-696.

Grosshans, H., Johnson, T., Reinert, K.L., Gerstein, M., and Slack, F.J. 2005. The temporal patterning microRNA let-7 regulates several transcription factors at the larval to adult transition in C. elegans. Dev. Cell 8: 321-330.

Grunstein, M. 1997a. Molecular model for telomeric heterochromatin in yeast. Curr. Opin. Cell Biol. 9: 383-387.

-1997b. Histone acetylation in chromatin structure and transcription. Nature 389: 349-352.

Gu, W., Szauter, P., and Lucchesi, J.C. 1998. Targeting of MOF, a putative histone acetyl transferase, to the $\mathrm{X}$ chromosome of Drosophila melanogaster. Dev. Genet. 22: 56-64.

Guo, S. and Kemphues, K.J. 1995. par-1, a gene required for establishing polarity in C. elegans embryos, encodes a putative Ser/Thr kinase that is asymmetrically distributed. Cell 81: 611-620.

Hall, I.M., Shankaranarayana, G.D., Noma, K., Ayoub, N., Cohen, A., and Grewal, S.I. 2002. Establishment and maintenance of a heterochromatin domain. Science 297: 22322237.

Hamilton, A., Voinnet, O., Chappell, L., and Baulcombe, D. 2002. Two classes of short interfering RNA in RNA silencing. EMBO J. 21: 4671-4679.

Hannon, G. 2002. RNA interference. Nature 418: 244-251.

He, L. and Hannon, G.J. 2004. MicroRNAs: Small RNAs with a big role in gene regulation. Nat. Rev. Genet. 5: 522-531.

Heard, E. 2004. Recent advances in X-chromosome inactivation. Curr. Opin. Cell Biol. 16: 247-255.

Hernandez-Munoz, I., Lund, A.H., van der Stoop, P., Boutsma, E., Muijrers, I., Verhoeven, E., Nusinow, D.A., Panning, B., Marahrens, Y., and van Lohuizen, M. 2005. Stable X chromosome inactivation involves the PRC1 Polycomb complex and requires histone MACROH2A1 and the CULLIN3/ SPOP ubiquitin E3 ligase. Proc. Natl. Acad. Sci. 102: 76357640.

Huertas, D., Cortes, A., Casanova, J., and Azorin, F. 2004. Drosophila DDP1, a multi-KH-domain protein, contributes to centromeric silencing and chromosome segregation. Curr. Biol. 14: 1611-1620.

Ikura, T., Ogryzko, V.V., Grigoriev, M., Groisman, R., Wang, J., Horikoshi, M., Scully, R., Qin, J., and Nakatani, Y. 2000. Involvement of the TIP60 histone acetylase complex in DNA repair and apoptosis. Cell 102: 463-473.

Jacobs, S.A. and Khorasanizadeh, S. 2002. Structure of HP1 chromodomain bound to a lysine 9-methylated histone $\mathrm{H} 3$ tail. Science 295: 2080-2083.

Jacobs, S.A., Taverna, S.D., Zhang, Y., Briggs, S.D., Li, J., Eissenberg, J.C., Allis, C.D., and Khorasanizadeh, S. 2001. Specificity of the HP1 chromo domain for the methylated N-terminus of histone H3. EMBO J. 20: 5232-5241.

Jensen, S., Gassama, M.P., and Heidmann, T. 1999. Taming of transposable elements by homology-dependent gene silencing. Nat. Genet. 21: 209-212.

Jenuwein, T. and Allis, C.D. 2001. Translating the histone code. Science 293: 1074-1080.

Johnston, R.J. and Hobert, O. 2003. A microRNA controlling left/right neuronal asymmetry in Caenorhabditis elegans. Nature 426: 845-849.

Jones, L., Ratcliff, F., and Baulcombe, D.C. 2001. RNA-directed transcriptional gene silencing in plants can be inherited independently of the RNA trigger and requires Met1 for maintenance. Curr. Biol. 11: 747-757.

Juarez, M.T., Kui, J.S., Thomas, J., Heller, B.A., and Timmermans, M.C. 2004. microRNA-mediated repression of rolled leaf1 specifies maize leaf polarity. Nature 428: 84-88.

Kamakaka, R.T. and Biggins, S. 2005. Histone variants: Deviants? Genes \& Dev. 19: 295-310.

Kanellopoulou, C., Muljo, S.A., Kung, A.L., Ganesan, S., Drapkin, R., Jenuwein, T., Livingston, D.M., and Rajewsky, K. 2005. Dicer-deficient mouse embryonic stem cells are defective in differentiation and centromeric silencing. Genes \& Dev. 19: 489-501.

Karpen, G.H. and Allshire, R.C. 1997. The case for epigenetic effects on centromere identity and function. Trends Genet. 13: 489-496.

Karras, G.I., Kustatscher, G., Buhecha, H.R., Allen, M.D., Pugieux, C., Sait, F., Bycroft, M., and Ladurner, A.G. 2005. The macro domain is an ADP-ribose binding module. EMBO $J$. 24: 1911-1920.

Kawasaki, H. and Taira, K. 2004. Induction of DNA methylation and gene silencing by short interfering RNAs in human cells. Nature 431: 211-217.

Kayne, P.S., Kim, U.J., Han, M., Mullen, J.R., Yoshizaki, F., and Grunstein, M. 1988. Extremely conserved histone H4 N terminus is dispensable for growth but essential for repressing the silent mating loci in yeast. Cell 55: 27-39.

Kelley, R.L. and Kuroda, M.I. 2000. The role of chromosomal RNAs in marking the $\mathrm{X}$ for dosage compensation. Curr. Opin. Genet. Dev. 10: 555-561.

Kellum, R. and Alberts, B.M. 1995. Heterochromatin protein 1 is required for correct chromosome segregation in Drosophila embryos. J. Cell Sci. 108: 1419-1431.

Kelly, W.G. and Fire, A. 1998. Chromatin silencing and the maintenance of a functional germline in Caenorhabditis elegans. Development 125: 2451-2456.

Kennerdell, J.R., Yamaguchi, S., and Carthew, R.W. 2002. RNAi is activated during Drosophila oocyte maturation in a manner dependent on aubergine and spindle-E. Genes \& Dev. 16: $1884-1889$.

Ketting, R.F., Haverkamp, T.H., van Leuven, H.G., and Plasterk, R.H. 1999. Mut7 of C. elegans, required for transposon silencing and RNA interference, is a homolog of Werner syndrome helicase and RNase D. Cell 99: 133-141. 
Kidner, C.A. and Martienssen, R.A. 2004. Spatially restricted microRNA directs leaf polarity through ARGONAUTE1. Nature 428: 81-84.

Kuzmichev, A., Nishioka, K., Erdjument-Bromage, H., Tempst, P., and Reinberg, D. 2002. Histone methyltransferase activity associated with a human multiprotein complex containing the Enhancer of Zeste protein. Genes \& Dev. 16: 28932905.

Lachner, M., O'Carroll, D., Rea, S., Mechtler, K., and Jenuwein, T. 2001. Methylation of histone H3 lysine 9 creates a binding site for HP1 proteins. Nature 410: 116-120.

Ladurner, A.G. 2003. Inactivating chromosomes: A macro domain that minimizes transcription. Mol. Cell 12: 1-4.

Lehnertz, B., Ueda, Y., Derijck, A.A., Braunschweig, U., PerezBurgos, L., Kubicek, S., Chen, T., Li, E., Jenuwein, T., and Peters, A.H. 2003. Suv39h-mediated histone H3 lysine 9 methylation directs DNA methylation to major satellite repeats at pericentric heterochromatin. Curr. Biol. 13: 11921200.

Lewis, B.P., Burge, C.B., and Bartel, D.P. 2005. Conserved seed pairing, often flanked by adenosines, indicates that thousands of human genes are microRNA targets. Cell 120: 1520.

Lindroth, A.M., Shultis, D., Jasencakova, Z., Fuchs, J., Johnson, L., Schubert, D., Patnaik, D., Pradhan, S., Goodrich, J., Schubert, I., et al. 2004. Dual histone H3 methylation marks at lysines 9 and 27 required for interaction with CHROMOMETHYLASE3. EMBO I. 23: 4286-4296.

Lingel, A., Simon, B., Izaurralde, E., and Sattler, M. 2003. Structure and nucleic-acid binding of the Drosophila Argonaute 2 PAZ domain. Nature 426: 465-469.

Lippman, Z., Gendrel, A.V., Black, M., Vaughn, M.W., Dedhia, N., McCombie, W.R., Lavine, K., Mittal, V., May, B., Kasschau, K.D., et al. 2004. Role of transposable elements in heterochromatin and epigenetic control. Nature 430: 471476.

Litt, M.D., Simpson, M., Recillas-Targa, F., Prioleau, M.N., and Felsenfeld G. 2001. Transitions in histone acetylation reveal boundaries of three separately regulated neighboring loci. EMBO J. 20: 2224-2235.

Liu, J., Carmell M.A., Rivas, F.V., Marsden C.G., Thomson, J.M., Song, J.J., Hammond, S.M., Joshua-Tor, L., and Hannon, G.J. 2004. Argonaute2 is the catalytic engine of mammalian RNAi. Science 305: 1437-1441.

Llave, C., Kasschau, K.D., Rector, M.A., and Carrington, J.C. 2002. Endogenous and silencing-associated small RNAs in plants. Plant Cell 14: 1605-1619.

Luger, K., Mader, A.W., Richmond, R.K., Sargent, D.F., and Richmond, T.J. 1997. Crystal structure of the nucleosome core particle at $2.8 \AA$ resolution. Nature 389: 251-260.

Ma, J.B., Ye, K., and Patel, D.J. 2004. Structural basis for overhang-specific small interfering RNA recognition by the PAZ domain. Nature 429: 318-322.

Madireddi, M.T., Davis, M.C., and Allis, C.D. 1994. Identification of a novel polypeptide involved in the formation of DNA-containing vesicles during macronuclear development in Tetrahymena. Dev. Biol. 165: 418-431.

Madireddi, M.T., Coyne, R.S., Smothers, J.F., Mickey, K.M., Yao, M.C., and Allis, C.D. 1996. Pddlp, a novel chromodomain-containing protein, links heterochromatin assembly and DNA elimination in Tetrahymena. Cell 87: 75-84.

Maison, C., Bailly, D., Peters, A.H.F.M., Quivy, J.P., Roche, D., Taddei, A., Lachner, M., Jenuwein, T., and Almouzni, G. 2002. Higher-order structure in pericentric heterochromatin involves a distinct pattern of histone modification and an RNA component. Nat. Genet. 30: 329-334.
Makeyev, E.V. and Bamford, D.H. 2002. Cellular RNA-dependent RNA polymerase involved in posttranscriptional gene silencing has two distinct activity modes. Mol. Cell 10: $1417-1427$.

Marahrens, Y., Panning, B., Dausman, J., Strauss, W., and Jaenisch, R. 1997. Xist-deficient mice are defective in dosage compensation but not spermatogenesis. Genes \& Dev. 11: 156-166.

Martens, J.H., O'Sullivan, R.J., Braunschweig, U., Opravil, S., Radolf, M., Steinlein, P., and Jenuwein, T. 2005. The profile of repeat-associated histone lysine methylation states in the mouse epigenome. EMBO J. 24: 800-812.

Martienssen, R.A. 2003. Maintenance of heterochromatin by RNA interference of tandem repeats. Nat. Genet. 35: 213214.

Matzke, M.A., Mette, M.F., and Matzke, A.J. 2000. Transgene silencing by the host genome defense: Implications for the evolution of epigenetic control mechanisms in plants and vertebrates. Plant Mol. Biol. 43: 401-415.

Maurer-Stroh, S., Dickens, N.J., Hughes-Davies, L., Kouzarides, T., Eisenhaber, F., and Ponting, C.P. 2003. The Tudor domain 'Royal Family': Tudor, plant Agenet, Chromo, PWWP and MBT domains. Trends Biochem. Sci. 28: 69-74.

McClintock, B. 1951. Chromosome organization and genic expression. Cold Spring Harb. Symp. Quant. Biol. 16: 13-47.

Meister, G. and Tuschl, T. 2004. Mechanisms of gene silencing by double-stranded RNA. Nature 431: 343-349.

Meister, G., Landthaler, M., Patkaniowska, A., Dorsett, Y., Teng, G., and Tuschl T. 2004. Human Argonaute2 mediates RNA cleavage targeted by miRNAs and siRNAs. Mol. Cell 15: $185-197$.

Meller, V.H. and Rattner, B.P. 2002. The roX genes encode redundant male-specific lethal transcripts required for targeting of the MSL complex. EMBO J. 21: 1084-1091.

Min, J., Zhang, Y., and Xu, R. 2003. Structural basis for specific binding of Polycomb chromodomain to histone H3 methylated at Lys 27. Genes \& Dev. 17: 1823-1828.

Mochizuki, K. and Gorovsky, M.A. 2004. Small RNAs in genome rearrangement in Tetrahymena. Curr. Opin. Genet. Dev. 14: 1-7.

- 2005. A Dicer-like protein in Tetrahymena has distinct functions in genome rearrangement, chromosome segregation, and meiotic prophase. Genes \& Dev. 19: 77-89.

Mochizuki, K., Fine, N.A., Fujisawa, T., and Gorovsky, M.A. 2002. Analysis of a piwi-related gene implicates small RNAs in genome rearrangement in Tetrahymena. Cell 110: 689699.

Morales, V., Straub, T., Neumann, M.F., Mengus, G., Akhtar, A., and Becker, P.B. 2004. Functional integration of the histone acetyltransferase MOF into the dosage compensation complex. EMBO J. 23: 2258-2268.

Morey, C. and Avner, P. 2004. Employment opportunities for non-coding RNAs. FEBS Lett. 567: 27-34.

Morris, K.V., Chan, S.W., Jacobsen, S.E., and Looney, D.J. 2004. Small interfering RNA-induced transcriptional gene silencing in human cells. Science 305: 1289-1292.

Motamedi, M.R., Verdel, A., Colmenares, S.U., Gerber, S.A., Gygi, S.P., and Moazed, D. 2004. Two RNAi complexes, RITS and RDRC, physically interact and localize to noncoding centromeric RNAs. Cell 119: 789-802.

Mourrain, P., Beclin, C., Elmayan, T., Feuerbach, F., Godon, C., Morel, J.B., Jouette, D., Lacombe, A.M., Nikic, S., Picault, N., et al. 2000. Arabidopsis SGS2 and SGS3 genes are required for posttranscriptional gene silencing and natural virus resistance. Cell 101: 533-542.

Muchardt, C., Guilleme, M., Seeler, J.S., Trouche, D., Dejean, 
A., and Yaniv, M. 2002. Coordinated methyl and RNA binding is required for heterochromatin localization of mammalian HP1 $\alpha$. EMBO Rep. 3: 975-981.

Muller, H.J. 1930. Types of visible variations induced by X-rays in Drosophila. J. Genet. 22: 299-334.

Nielsen, P.R., Nietlispach, D., Mott, H.R., Callaghan, J., Bannister, A., Kouzarides, T., Murzin, A.G., Murzina, N.V., and Laue, E.D. 2002. Structure of the HP1 chromodomain bound to histone H3 methylated at lysine 9. Nature 416: 103-107.

Nikiforov, M.A., Smothers, J.F., Gorovsky, M.A., and Allis, C.D. 1999. Excision of micronuclear-specific DNA requires parental expression of pdd2p and occurs independently from DNA replication in Tetrahymena thermophila. Genes \& Dev. 13: 2852-2862.

Nikiforov, M.A., Gorovsky, M.A., and Allis, C.D. 2000. A novel chromodomain protein, pdd3p, associates with internal eliminated sequences during macronuclear development in Tetrahymena thermophila. Mol. Cell. Biol. 20: 4128-4134.

Noma, K., Allis, C.D., and Grewal, S.I. 2001. Transitions in distinct histone $\mathrm{H} 3$ methylation patterns at the heterochromatin domain boundaries. Science 293: 1150-1155.

Noma, K., Sugiyama, T., Cam, H., Verdel, A., Zofall, M., Jia, S., Moazed, D., and Grewal, S.I. 2004. RITS acts in cis to promote RNA interference-mediated transcriptional and posttranscriptional silencing. Nat. Genet. 36: 1174-1180.

Ohhata, T., Tachibana, M., Tada, M., Tada, T., Sasaki, H., Shinkai, Y., and Sado, T. 2004. X-Inactivation is stably maintained in mouse embryos deficient for histone methyltransferase G9a. Genesis 40: 151-156.

O'Neill, M.J. 2005. The influence of non-coding RNAs on allelespecific gene expression in mammals. Hum. Mol. Genet. 14: R113-R120.

Palatnik, J.F., Allen, E., Wu, X., Schommer, C., Schwab, R., Carrington, J.C., and Weigel, D. 2003. Control of leaf morphogenesis by microRNAs. Nature 425: 257-263.

Pal-Bhadra, M., Bhadra, U., and Birchler, J.A. 1997. Cosuppression in Drosophila: Gene silencing of alcohol dehydrogenase by white-Adh transgenes is Polycomb dependent. Cell 90: 479-490.

- 2002. RNAi related mechanisms affect both transcriptional and posttranscriptional transgene silencing in Drosophila. Mol. Cell 9: 315-327.

Pal-Bhadra, M., Leibovitch, B.A., Gandhi, S.G., Rao, M., Bhadra, U., Birchler, J.A., and Elgin, S.C. 2004. Heterochromatic silencing and HP1 localization in Drosophila are dependent on the RNAi machinery. Science 303: 669-672.

Park, C.W., Chen, Z., Kren, B.T., and Steer, C.J. 2004. Doublestranded siRNA targeted to the huntingtin gene does not induce DNA methylation. Biochem. Biophys. Res. Commun. 323: 275-280.

Paro, R. and Hogness, D. 1991. The Polycomb protein shares a homologous domain with a heterochromatin-associated protein of Drosophila. Proc. Nat1. Acad. Sci. 88: 263-267.

Partridge, J.F., Scott, K.S., Bannister, A.J., Kouzarides, T., and Allshire, R.C. 2002. cis-acting DNA from fission yeast centromeres mediates histone $\mathrm{H} 3$ methylation and recruitment of silencing factors and cohesin to an ectopic site. Curr. Biol. 12: $1652-1660$.

Pehrson, J.R. and Fried, V.A. 1992. MacroH2A, a core histone containing a large nonhistone region. Science 257: 13981400.

Pelissier, T. and Wassenegger, M. 2000. A DNA target of $30 \mathrm{bp}$ is sufficient for RNA-directed DNA methylation. RNA 6: 55-65.

Penny, G.D., Kay, G.F., Sheardown, S.A., Rastan, S., and Brockdorff, N. 1996. Requirement for Xist in X chromosome in- activation. Nature 379: 131-137.

Pfeffer, S., Zavolan, M., Grasser, F.A., Chien, M., Russo, J.J., Ju, J., John, B., Enright, A.J., Marks, D., Sander, C., et al. 2004. Identification of virus-encoded microRNAs. Science 304: 734-736.

Plath, K., Fang, J., Mlynarczyk-Evans, S.K., Cao, R., Worringer, K.A., Wang, H., de la Cruz, C.C., Otte, A.P., Panning, B., and Zhang, Y. 2003. Role of histone H3 lysine 27 methylation in $\mathrm{X}$ inactivation. Science 300: 131-135.

Plath, K., Talbot, D., Hamer, K.M., Otte, A.P., Yang, T.P., Jaenisch, R., and Panning, B. 2004. Developmentally regulated alterations in Polycomb repressive complex 1 proteins on the inactive X chromosome. J. Cell Biol. 167: 1025-1035.

Poy, M.N., Eliasson, L., Krutzfeldt, J., Kuwajima, S., Ma, X., Macdonald, P.E., Pfeffer, S., Tuschl, T., Rajewsky, N., Rorsman, P., et al. 2004. A pancreatic islet-specific microRNA regulates insulin secretion. Nature 432: 226-230.

Prescott, D.M. 1994. The DNA of ciliated protozoa. Microbiol. Rev. 58: 233-267.

Provost, P., Silverstein, R.A., Dishart, D., Walfridsson, J., Djupedal, I., Kniola, B., Wright, A., Samuelsson, B., Radmark, O., and Ekwall, K. 2002. Dicer is required for chromosome segregation and gene silencing in fission yeast cells. Proc. Natl. Acad. Sci. 99: 16648-16653.

Reinhart, B.J. and Bartel, D.P. 2002. Small RNAs correspond to centromere heterochromatic repeats. Science 297: 1831.

Richter, L., Bone, J.R., and Kuroda, M.I. 1996. RNA-dependent association of the Drosophila maleless protein with the male X chromosome. Genes Cells 1: 325-336.

Ringrose, L. and Paro, R. 2004. Epigenetic regulation of cellular memory by the Polycomb and Trithorax group proteins. Annu. Rev. Genet. 38: 413-443.

Robert, V.J.P., Sijen, T., van Wolfswinkel, J., and Plasterk, R.H.A. 2005. Chromatin and RNAi factors protect the C. elegans germline against repetitive sequences. Genes \& Dev. 19: 782-787.

Rougeulle, C., Chaumeil, J., Sarma, K., Allis, C.D., Reinberg, D., Avner, P., and Heard, E. 2004. Differential histone H3 Lys-9 and Lys-27 methylation profiles on the X chromosome. Mol. Cell. Biol. 24: 5475-5484.

Saurin, A.J., Shiels, C., Williamson, J., Satijn, D.P., Otte, A.P., Sheer, D., and Freemont, P.S. 1998. The human Polycomb group complex associates with pericentromeric heterochromatin to form a novel nuclear domain. J. Cell Biol. 142: 887898.

Schotta, G., Ebert, A., Dorn, R., and Reuter, G. 2003. Positioneffect variegation and the genetic dissection of chromatin regulation in Drosophila. Semin. Cell Dev. Biol. 14: 67-75.

Schramke, V. and Allshire, R. 2003. Hairpin RNAs and retrotransposon LTRs effect RNAi and chromatin-based gene silencing. Science 301: 1069-1074.

Selenko, P., Sprangers, R., Stier, G., Buhler, D., Fischer, U., and Sattler, M. 2001. SMN Tudor domain structure and its interaction with the Sm proteins. Nat. Struct. Biol. 8: 27-31.

Shi, Y., Lan, F., Matson, C., Mulligan, P., Whetstine, J.R., Cole, P.A., Casero, R.A., and Shi, Y. 2004. Histone demethylation mediated by the nuclear amine oxidase homolog LSD1. Cell 119: 941-953.

Sijen, T. and Plasterk, R.H. 2003. Transposon silencing in the Caenorhabditis elegans germ line by natural RNAi. Nature 426: 310-314.

Silva, J., Mak, W., Zvetkova, I., Appanah, R., Nesterova, T.B., Webster, Z., Peters, A.H., Jenuwein, T., Otte, A.P., and Brockdorff, N. 2003. Establishment of histone H3 methylation on the inactive $\mathrm{X}$ chromosome requires transient recruitment of Eed-Enxl polycomb group complexes. Dev. 
Cell 4: 481-495.

Smothers, J.F., Mizzen, C.A., Tubbert, M.M., Cook, R.G., and Allis, C.D. 1997. Pddlp associates with germline-restricted chromatin and a second novel anlagen-enriched protein in developmentally programmed DNA elimination structures. Development 124: 4537-4545.

Song, J.J., Liu, J., Tolia, N.H., Schneiderman, J., Smith, S.K., Martienssen, R.A., Hannon, G.J., and Joshua-Tor, L. 2003. The crystal structure of the Argonaute2 PAZ domain reveals an RNA binding motif in RNAi effector complexes. Nat. Struct. Biol. 10: 1026-1032.

Song, J.J., Smith, S.K., Hannon, G.J., and Joshua-Tor, L. 2004. Crystal structure of Argonaute and its implications for RISC slicer activity. Science 305: 1434-1437.

Sontheimer, E.J. 2005. Assembly and function of RNA silencing complexes. Nat. Rev. Mol. Cell Biol. 6: 127-138.

Sprangers, R., Groves, M.R., Sinning, I., and Sattler, M. 2003. High-resolution X-ray and NMR structures of the SMN Tudor domain: Conformational variation in the binding site for symmetrically dimethylated arginine residues. J. Mol. Biol. 327: 507-520.

Strahl, B.D. and Allis, C.D. 2000. The language of covalent histone modifications. Nature 403: 41-45.

Svoboda, P., Stein, P., Anger, M., Bernstein, E., Hannon, G.J., and Schultz, R.M. 2004a. RNAi and expression of retrotransposons MuERV-L and IAP in preimplantation mouse embryos. Dev. Biol. 269: 276-285.

Svoboda, P., Stein, P., Filipowicz, W., and Schultz, R.M. 2004b. Lack of homologous sequence-specific DNA methylation in response to stable dsRNA expression in mouse oocytes. Nucleic Acids Res. 32: 3601-3606.

Tabara, H., Sarkissian, M., Kelly, W.G., Fleenor, J., Grishok, A., Timmons, L., Fire, A., and Mello, C.C. 1999. The rde-1 gene, RNA interference, and transposon silencing in C. elegans. Cell 99: 123-132.

Taverna, S.D., Coyne, R.S., and Allis, C.D. 2002. Methylation of histone $\mathrm{H} 3$ at lysine 9 targets programmed DNA elimination in Tetrahymena. Cell 110: 701-711.

Tomari, Y. and Zamore, P.D. 2005. Perspective: Machines for RNAi. Genes \& Dev. 19: 517-529.

Turner, B.M. 1993. Decoding the nucleosome. Cell. 75: 5-8.

2000. Histone acetylation and an epigenetic code. Bioessays 22: $836-845$.

Verdel, A., Jia, S., Gerber, S., Sugiyama, T., Gygi, S., Grewal, S.I., and Moazed, D. 2004. RNAi-mediated targeting of heterochromatin by the RITS complex. Science 303: 672-676.

Volpe, T.A., Kidner, C., Hall, I.M., Teng, G., Grewal, S.I., and Martienssen, R.A. 2002. Regulation of heterochromatic silencing and histone H3 lysine-9 methylation by RNAi. Science 297: 1833-1837.

Wallrath, L.L. and Elgin, S.C.R. 1995. Position effect variegation in Drosophila is associated with an altered chromatin structure. Genes \& Dev. 9: 1263-1277.

Wang, Y., Wysocka, J., Sayegh, J., Lee, Y.H., Perlin, J.R., Leonelli, L., Sonbuchner, L.S., McDonald, C.H., Cook, R.G., Dou, Y., et al. 2004. Human PAD4 regulates histone arginine methylation levels via demethylimination. Science 306: 279-283.

Wassenegger, M., Heimes, S., Riedel, L., and Sanger, H.L. 1994. RNA-directed de novo methylation of genomic sequences in plants. Cell 76: 567-576.

Wuitschick, J.D. and Karrer, K.M. 2003. Diverse sequences within Tlr elements target programmed DNA elimination in Tetrahymena thermophila. Eukaryot. Cell 2: 678-689.

Wutz, A., Rasmussen, T.P., and Jaenisch, R. 2002. Chromosomal silencing and localization are mediated by different domains of Xist RNA. Nat. Genet. 30: 167-174.

Yan, K.S., Yan, S., Farooq, A., Han, A., Zeng, L., and Zhou, M.M. 2003. Structure and conserved RNA binding of the PAZ domain. Nature 426: 468-474.

Yao, M.-C., Fuller, P., and Xi, X. 2003. Programmed DNA deletion as an RNA-guided system of genome defense. Science 300: 1581-1584.

Zhang, Y. and Reinberg, D. 2001. Transcription regulation by histone methylation: Interplay between different covalent modifications of the core histone tails. Genes \& Dev. 15: 2343-2360.

Zhang, H., Christoforou, A., Aravind, L., Emmons, S.W., van den Heuvel, S., and Haber, D.A. 2004. The C. elegans Polycomb gene SOP-2 encodes an RNA binding protein. Mol. Cell 14: 841-847.

Zilberman, D., Cao, X., and Jacobsen, S.E. 2003. ARGONAUTE4 control of locus-specific siRNA accumulation and DNA and histone methylation. Science 299: 716-719. 


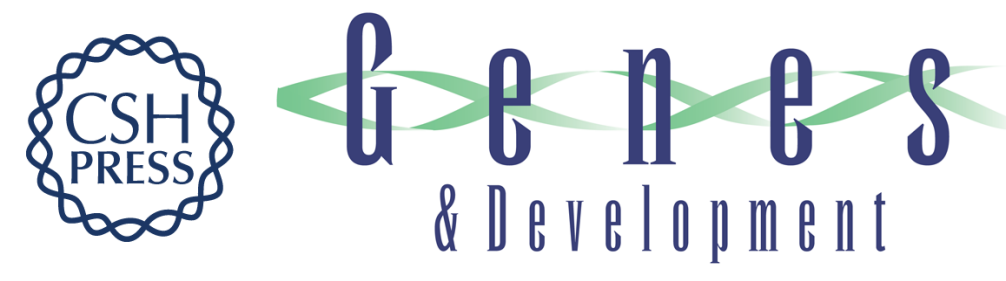

\section{RNA meets chromatin}

\section{Emily Bernstein and C. David Allis}

Genes Dev. 2005, 19:

Access the most recent version at doi:10.1101/gad.1324305

$\begin{array}{ll}\text { References } & \text { This article cites } 177 \text { articles, } 68 \text { of which can be accessed free at: } \\ \text { http://genesdev.cshlp.org/content/19/14/1635.full.html\#ref-list-1 }\end{array}$

\section{License} Email Alerting
Service $\begin{aligned} & \text { Receive free email alerts when new articles cite this article - sign up in the box at the top } \\ & \text { right corner of the article or click here. }\end{aligned}$

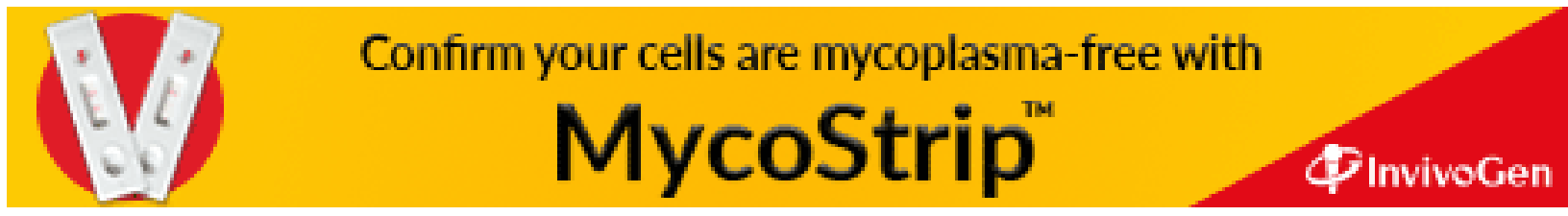

